\title{
EPPUR SI MUOVE!: NUEVOS CAMINOS JURISPRUDENCIALES PARA LA PROTECCIÓN DE LOS DERECHOS SOCIALES DE LOS MIGRANTES INDOCUMENTADOS EN EUROPA'
}

CARMEN PÉREZ GONZÁLEZ Y FRANCESCA IPPOLITO²

\author{
Revista de Derecho Comunitario Europeo \\ ISSN-L 1138-4026, núm. 53, Madrid, enero/abril (2016), pp. 79-116 \\ http://dx.doi.org/10.18042/cepc/rdce.53.02 \\ Cómo citar/Citation \\ Pérez González, C. e Ippolito, F. (2016). Eppur si muove!: nuevos caminos \\ jurisprudenciales para la protección de los derechos sociales \\ de los migrantes indocumentados en Europa. \\ Revista de Derecho Comunitario Europeo, 53, 79-116. \\ doi: http://dx.doi.org/10.18042/cepc/rdce.53.02
}

\section{Resumen}

El propósito de este trabajo es explorar de qué modo el Tribunal de Justicia de la Unión Europea se ha valido de los conceptos de dignidad humana y vulnerabilidad para proteger determinados derechos sociales de los inmigrantes que se encuentran en situación administrativa irregular en el territorio de la Unión. Con ese fin se realiza un análisis comparativo de esa jurisprudencia con la emanada de otros órganos europeos de protección de derechos humanos: el Tribunal Europeo de Derechos Humanos y

1 Una versión preliminar de este trabajo, más breve y menos elaborada, fue presentada en forma de comunicación durante las XXVI Jornadas de la AEPDIRI «España y la UE en el orden internacional», celebradas en la Universidad de Sevilla los días 15 y 16 de octubre de 2015. Las autoras agradecen a los evaluadores anónimos sus comentarios para la mejora de este trabajo.

2 Carmen PÉREZ GONZÁLEZ es profesora titular de Derecho Internacional Público y Relaciones Internacionales, Universidad Carlos III de Madrid, y Francesca IPPOLITO es professore associato di Diritto dell'Unione europea, Università degli Studi di Cagliari. 
el Comité Europeo de Derechos Sociales. Se trataría de analizar, en este sentido, si cabría hablar de un diálogo judicial en lo que hace al establecimiento de un estándar mínimo de derechos socio-económicos de los inmigrantes en situación administrativa irregular en Europa y de qué modo ha contribuido a ello la jurisprudencia del Tribunal de Justicia. De otro lado, se valora si puede hablarse en este ámbito de un diálogo vertical. Se analiza, en concreto, de qué modo han contribuido a este debate los Tribunales Constitucionales de algunos Estados miembros, en particular el español, y si su doctrina coincide con la avanzada internacionalmente.

\section{Palabras clave}

Dignidad humana; vulnerabilidad; derechos sociales; inmigrantes en situación administrativa irregular; diálogo judicial; Tribunal de Justicia de la Unión Europea; Tribunal Europeo de Derechos Humanos; Comité Europeo de Derechos Sociales; Tribunales Constitucionales de los Estados miembros.

\section{EPPUR SI MUOVE!: NEW JUDICIAL PATHS FOR THE PROTECTION OF SOCIAL RIGHTS OF UNDOCUMENTED MIGRANTS IN EUROPE}

\section{Abstract}

This work aims to analyze how the Court of Justice of the European Union has founded the protection of certain social rights of irregular migrants in the notions of human dignity and vulnerability. For that purpose, the paper addresses a comparative analysis of the European Court of Justice's case law and the jurisprudence of other European human rights mechanisms: The European Court of Human Rights and the European Committee of Social Rights. The authors try to explore, in this sense, if it is possible to talk about a judicial dialogue aiming to the establishment of a minimum standard of socio-economic rights of irregular migrants in Europe and how the European Court of Justice's case-law has contributed to it. Finally, the paper evaluates if we can talk about a vertical judicial dialogue in this regard. In particular, it examines how the Constitutional Court of certain Member States, in particular the Spanish Constitutional Court, have contributed to this debate and if their case law meets the international human rights law standards.

\section{Key words}

Human dignity; vulnerability; social rights; irregular migrants; judicial dialogue; Court of Justice of the European Union; European Court of Human Rights; European Committee of Social Rights; Constitutional Courts of the Member States. 


\section{EPPUR SI MUOVE!: NOUVEAUX CHEMINS JUDICIAIRES POUR LA PROTECTION DES DROITS SOCIAUX DES MIGRANTS EN SITUATION IRRÉGULIÈRE DANS L'EUROPE}

\section{Résumé}

Cet article vise à examiner comment la Cour de Justice de l'Union européenne s'est servie des notions de dignité humaine et vulnérabilité pour protéger certains droits sociaux des migrants en situation irrégulière. L'étude ensuite présente une analyse comparative de cette jurisprudence avec celle établie par autres systèmes européens de protection des droits de l'homme: la Cour européenne des droits de l'homme et le Comité européen des Droits sociaux. Il s'agit d'analyser si on peut parler d'un dialogue judiciaire relatif à l'établissement d'un standard minimum des droits socio-économiques des migrants en situation irrégulière dans l'Europe et comment la jurisprudence de la Cour de Justice a contribué à son développement. On examine, en outre, si on peut parler d'un dialogue vertical concernant cette question. En somme, on analyse comment certaines Cours constitutionnelles des États Membres, notamment la Cour constitutionnelle espagnole, ont contribué à ce débat et si sa doctrine s'adapte aux standards internationaux des droits de l'homme.

\section{Mots clés}

Dignité humaine; vulnérabilité; droits sociaux; migrants en situation irrégulière; dialogue judiciaire; Cour de Justice de l'Union européenne; Cour européenne des droits de l'homme; Comité européen des Droits sociaux; Cours constitutionnelles des États membres.

\section{SUMARIO}

I. ALGUNAS PRECISIONES INTRODUCTORIAS SOBRE EL DERECHO INTERNACIONAL DE LOS DERECHOS HUMANOS Y LOS INMIGRANTES EN SITUACIÓN ADMINISTRATIVA IRREGULAR. II. LA PROTECCIÓN DE LA DIGNIDAD HUMANA Y FRENTE A LA VULNERABILIDAD COMO FUNDAMENTO DE LA EXTENSIÓN JURISPRUDENCIAL DE LOS DERECHOS SOCIALES A LOS INMIGRANTES EN SITUACIÓN ADMINISTRATIVA IRREGULAR: 1. La dignidad humana como límite; 2. La vulnerabilidad como fundamento; 3 . La combinación de la dignidad humana y la noción de vulnerabilidad. III. ¿̇UN DIÁLOGO VERTICAL? LOS TRIBUNALES CONSTITUCIONALES DE LOS ESTADOS MIEMBROS FRENTE A LA CUESTIÓN DE LA GARANTÍA DE LOS DERECHOS SOCIALES A LOS INMIGRANTES EN SITUACIÓN ADMINISTRATIVA IRREGULAR: ESPECIAL REFERENCIA AL CASO ESPAÑOL. IV. CONCLUSIONES: «EPPUR SI MUOVE!». 


\section{ALGUNAS PRECISIONES INTRODUCTORIAS SOBRE EL DERECHO INTERNACIONAL DE LOS DERECHOS HUMANOS Y LOS INMIGRANTES EN SITUACIÓN ADMINISTRATIVA IRREGULAR}

Aunque el objetivo principal de este trabajo se circunscribe al ámbito europeo, no puede dejar de señalarse, como punto de partida del mismo, que el Derecho Internacional de los Derechos Humanos (DIDH) ha caracterizado a los inmigrantes en situación administrativa irregular como un colectivo particularmente vulnerable ${ }^{3}$ y que ha tratado de imponer a los Estados en cuyo territorio se encuentran obligaciones tendentes a la protección de sus derechos, también de naturaleza social y económica ${ }^{4}$. La labor del Relator Especial sobre los derechos humanos de los migrantes del Consejo de Derechos Humanos de Naciones Unidas, en el ámbito extraconvencional, y del Comité de Trabajadores Migrantes, en el convencional, es particularmente relevante en este sentido 5 . Otros órganos del sistema han apuntado en la misma direc-

3 Tal y como la doctrina ha señalado, la noción de vulnerabilidad juega un papel fundamental en el ámbito del DIDH y en la necesaria determinación de las necesidades (vulnerabilidades, podríamos decir) que deben ser merecedoras de protección. Se trata de un concepto, desde luego, impreciso. BESSON nos ofrece una definición: «D’une manière générale, on peut dire de la vulnérabilité qu'il s'agit de la qualité de l'individu ou du groupe susceptible de faire l'objet d'une atteinte à ses intérêts, c'est-à-dire la qualité de celles et ceux qui sont menacés de ces atteintes à leurs intérêts», Samantha BEESON, «La vulnérabilité et la structure des droits de l'homme. L'exemple de la jurisprudence de la Cour Européenne des Droits de l'Homme», en Laurence BURGORGUE LARSEN (dir.), La vulnérabilité saisie par les juges en Europe, Pedone, Paris, 2014, pp. 59-85, p. 60. Véase también Alexandre MORAWA, «Vulnerability as a Concept of International Human Rights Law», Journal of International Relations and Development, vol. 6, núm. 2, 2003, pp. 139-155.

4 Véase el Informe de la Alta Comisionada de las Naciones Unidas para los Derechos Humanos relativo a las obligaciones de los Estados respecto a los derechos económicos, sociales y culturales de todos los migrantes (E/2010/89, de 1 de junio de 2010), disponible en http://www.un.org/Docs/journal/asp/ws.asp?m=E/2010/89 (consultado por última vez el 17.10.2015). Se afirma en el mismo que la situación administrativa del inmigrante no debería ser tenida en cuenta, por ejemplo, por lo que se refiere a los sistemas de protección social dirigidos a aliviar la extrema pobreza o la vulnerabilidad (apdo. 46).

5 Una de las dos Observaciones Generales adoptadas hasta el momento por el Comité de Trabajadores Migrantes se centra, precisamente, en los derechos de los trabajadores migratorios en situación irregular y sus familiares: $c f r$ la Observación General núm. 2, adoptada el 28 de agosto de 2013, disponible en la siguiente dirección electrónica: http://tbinternet.ohchr.org/_layouts/treatybodyexternal/TBSearch.aspx?Lang=en\&- 
ción. Es el caso del Comité de Derechos Económicos, Sociales y Culturales ${ }^{6} \mathrm{y}$ del Comité para la Eliminación de la Discriminación Racial7

Los sistemas de protección regional de derechos humanos han asumido también esa vulnerabilidad y han tratado de avanzar en la misma línea. Aunque, como se ha dicho, este trabajo pretende analizar los desarrollos jurisprudenciales que se han dado en el ámbito europeo en relación con la protección de los derechos socio-económicos de los inmigrantes en situación administrativa irregular, no puede dejar de mencionarse, por lo avanzado de sus conclusiones, que también en el ámbito interamericano esto ha sido asi ${ }^{8}$.

TreatyID=7\&DocTypeID=11 (consultado por última vez el 17.10.2015). En la misma, el Comité asume que los trabajadores migratorios en situación administrativa irregular se encuentran per se en una situación de extrema vulnerabilidad (apdo. 16).

6 En su Observación General núm. 20 relativa a la no discriminación y los derechos económicos, sociales y culturales (art. 2, párrafo 2 del Pacto Internacional de Derechos Económicos, Sociales y Culturales) (E/C.12/GC/20, de 20 de julio de 2009), el Comité afirmó, por ejemplo, que «todos los niños de un Estado, incluidos los indocumentados, tienen derecho a recibir una educación y una alimentación adecuada y una atención sanitaria asequible. Los derechos reconocidos en el Pacto son aplicables a todos, incluidos los no nacionales, como los refugiados, los solicitantes de asilo, los apátridas, los trabajadores migratorios y las víctimas de la trata internacional, independientemente de su condición jurídica y de la documentación que posean» (apdo. 30). La Observación General está disponible en la siguiente dirección electrónica: http://tbinternet.ohchr.org/_layouts/treatybodyexternal/TBSearch.aspx?Lang=en \& TreatyID=9\&DocTypeID=11 (consultado por última vez el 17.10.2015).

7 En su Recomendación General núm. XXX sobre la discriminación contra los no ciudadanos (2005), el Comité señala, por ejemplo, que «si bien los Estados Partes pueden negarse a ofrecer empleo a los no ciudadanos que no posean un permiso de trabajo, todas las personas deberán poder disfrutar de los derechos laborales y de empleo» (apdo. 35). La Recomendación General está disponible en la siguiente dirección electrónica: http://tbinternet.ohchr.org/_layouts/treatybodyexternal/TBSearch.aspx?Lang=en\&TreatyID=6\&DocTypeID=11, consultado por última vez el 17.10.2015).

8 El sistema africano de protección de derechos humanos ofrece igualmente ejemplos interesantes. Es el caso de la Observación General núm. 2 del Comité Africano de Expertos sobre los Derechos y el Bienestar del Niño, relativa al derecho al nombre y la nacionalidad (CAEDBE/OG/02, 2014), disponible en la siguiente dirección electrónica: http://www.acerwc.org/general-comments/ (consultado por última vez el 17.10.2015). En la misma, el Comité considera que los niños en situación administrativa irregular, que se encontrarían en una situación de especial vulnerabilidad, tienen derecho a ser registrados como un modo de garantizar el acceso a determinados 
Un único art. de la Convención Americana sobre Derechos Humanos $(\mathrm{CADH})^{9}$, el 26, prevé la protección de derechos de naturaleza económica, social y cultural. Además, un protocolo adicional a la $\mathrm{CADH}$ en el ámbito de los derechos económicos, sociales y culturales se firmó en San Salvador en $1988^{10}$. Pero, a pesar del amplio número de derechos garantizados en el mismo, únicamente las violaciones de los derechos protegidos por el art. 8.a) (derecho a la organización de sindicatos y a la afiliación a los mismos) y por el art. 13 (derecho a la educación) que sean directamente imputables a un Estado parte, podrían dar lugar, mediante la participación de la Comisión Interamericana de Derechos Humanos, y cuando proceda de la Corte Interamericana de Derechos Humanos (CtIADH), a la aplicación del sistema de peticiones individuales regulado por los arts. 44 a 51 y 61 a 69 de la $C_{A D H}{ }^{11}$. Esto es, el protocolo únicamente extiende la jurisdicción ratione materiae de la Comisión Interamericana de Derechos Humanos y de la CtIADH a estos dos derechos ${ }^{12}$. Se trata, no cabe duda, de una limitación evidente. Para tratar de superarla, la doctrina ha propuesto diferentes fórmulas a través de las cuales lograr la justiciabilidad de los derechos económicos, sociales y culturales.

Así, se ha afirmado la aplicabilidad directa del mencionado art. 26 de la $\mathrm{CADH}$ respecto de cualquier derecho de naturaleza económica, social y cultural (aproximación directa); se ha propugnado que diferentes reglas procedimentales o el derecho a una igual protección ante la ley ${ }^{13}$ podrían servir

derechos y paliar así dicha vulnerabilidad. Entre esos derechos el Comité incluye algunos de carácter socio-económico (como el derecho a la salud o la educación).

9 Firmada en San José de Costa Rica el 22 de noviembre de 1969, disponible en http:// www.oas.org/dil/esp/tratados_B-32_Convencion_Americana_sobre_Derechos_Humanos.htm, (consultado por última vez el 17.10.2015).

10 Disponible en http://www.oas.org/juridico/spanish/tratados/a-52.html, (consultado por última vez el 17.10.2015).

11 Cfr. el art. 19.6 del Protocolo de San Salvador.

12 Oswaldo R. RUIZ-CHIRIBOGA, "The American Convention and the Protocol of San Salvador: Two Intertwined Treaties. Non-Enforceability of Economic, Social and Cultural Rights in the Inter-American System», Netherlands Quarterly of Human Rights, vol. 31, núm. 2, 2013, pp. 156-183, p. 161.

13 La CtIADH ha considerado que este derecho está contenido en una norma de ius cogens (Opinión Consultiva sobre la condición jurídica y derechos de los migrantes indocumentados, OC-18/03 de 17 de septiembre de 2003, apdo. 101; sentencia dictada en el caso Servellón García y otros vs. Honduras, de 21 de septiembre de 2006, apdo. 94; sentencia dictada en el caso Comunidad Indígena Xákmok Kásek vs. Paraguay. Fondo, Reparaciones y Costas, de 24 de agosto de 2010, apdo. 269; sentencia dictada en el caso Vélez Loor vs. Panamá. Excepciones Preliminares, Fondo, Reparaciones y Costas, 
de base para la alegación de vulneraciones de este tipo de derechos ante los órganos de protección del sistema (aproximación indirecta); se ha defendido la protección de determinados «elementos» de carácter económico, social o cultural de los derechos civiles y políticos (aproximación de la integración o de los elementos) y se ha mantenido que la justiciabilidad de los derechos económicos, sociales y culturales podría lograrse a través de la implementación de medidas de reparación (aproximación reparadora) ${ }^{14}$. Lo que interesa destacar aquí, sin embargo, es que los órganos de protección del sistema interamericano de derechos humanos se han servido de las nociones de dignidad humana y vulnerabilidad para garantizar en determinados casos la protección de los derechos sociales de los migrantes indocumentados. De importancia fundamental en este sentido son las opiniones consultivas de la CtIADH ${ }^{15}$.

de 23 de noviembre de 2010, apdo. 248). Sin embargo, en la última sentencia citada, la Corte recordó que aunque los Estados no pueden discriminar a los migrantes o tolerar discriminaciones que les perjudiquen, sí pueden otorgar un trato distinto a los migrantes documentados con respecto de los migrantes indocumentados, o entre migrantes y nacionales, siempre y cuando este trato diferencial sea razonable, objetivo, proporcional, y no lesione los derechos humanos. Todas las decisiones de la CtIADH citadas a lo largo del trabajo están disponibles en http://www.corteidh.or.cr/ (consultado por última vez el 17.10.2015).

14 Puede verse un análisis de la cuestión en Mónica FERIA TINTA, «Justiciability of Economic, Social, and Cultural Rights in the Inter-American System of Protection of Human Rights: Beyond Traditional Paradigms and Notios», Human Rights Quarterly, vol. 29, núm. 2, 2007, pp. 432-459, y Óscar PARRA VEGA, Justiciabilidad de los derechos económicos, sociales y culturales ante el sistema interamericano, Comisión $\mathrm{Na}$ cional de Derechos Humanos, México D.F., 2011.

15 La Opinión Consultiva sobre la condición juridica y derechos de los migrantes indocumentados ha sido calificada como el intento más significativo y notable, a nivel regional, de clarificar el marco jurídico aplicable a los migrantes en situación administrativa irregular: Dorothy ESTRADA-TANCK, «Human Security and Universal Human Rights of Undocumented Migrants: Transnational Vulnerabilities and Regional Traditions», ESIL Conference Paper 1/2012, disponible en la siguiente dirección electrónica: http:// ssrn.com/abstract=2193743 (consultado por última vez el 17.10.2015), p. 7. En esta ocasión, la Corte afirmó que en el marco de la $\mathrm{CADH}$, el principio de igualdad y no discriminación se aplica plenamente a las condiciones de trabajo de los trabajadores migratorios, estén documentados o no. Partiendo de la situación de particular vulnerabilidad en la que se encuentran los que no lo están, la Corte señaló que el disfrute de tales derechos, entre los que se encuentran el derecho a recibir un salario justo por el trabajo realizado, el derecho de acceso a la Seguridad Social, el derecho a que la duración de la jornada sea razonable y se realice en condiciones laborales adecuadas de seguridad e higiene, o el derecho al descanso, garantiza a todos los trabajadores 
En el caso, ya, de la Unión Europea (UE), nos encontramos con una situación jurídica particular. $Y$ es que el estatuto jurídico de los inmigrantes que se encuentran en situación administrativa irregular ha sido marginado en las iniciativas adoptadas por ella en el marco de la llamada política común de inmigración. Y esto es particularmente cierto en relación con los derechos de carácter socio-económico. Las normas del Derecho de la UE se aplican, en general, a aquellos nacionales de terceros Estados miembros que se encuentran residiendo legalmente en el territorio de la Unión. Así lo disponen expresamente los arts. 79.1 del Tratado de Funcionamiento de la Unión Europea (TFUE), que incluye entre los objetivos de la política común de inmigración de la UE la garantía de «un trato equitativo de los nacionales de terceros paises que residan legalmente en los Estados miembros» y 79.2, que dispone que con ese propósito se adoptarán medidas relativas a la definición de sus derechos ${ }^{16}$. Como consecuencia de ello,

migratorios y sus familiares «el disfrute de una vida digna» (Cfr. los apdos. 109, 133, 134, 156 y 157 de la OC-18/03). Debe citarse también la más reciente Opinión Consultiva sobre derechos y garantías de niñas y niños en el contexto de la migración y/o en necesidad de protección internacional (OC-21/14 de 19 de agosto de 2014). También en esta ocasión, vulnerabilidad y dignidad - junto con la obligación de preservar su interés superior - sirven a la Corte para trazar el mapa de las obligaciones que incumben al Estado en relación con la protección de los derechos de los menores inmersos en procesos migratorios, también de los derechos de naturaleza social y económica (alojamiento adecuado, educación, asistencia médica) y con independencia de su condición administrativa. Cfr., por ejemplo, los apdos. 106 (en relación con los menores potenciales víctimas de trata de seres humanos y por tanto en situación de vulnerabilidad extrema), 171-184 (en relación con las condiciones básicas que deben cumplir los lugares de alojamiento de niños y niñas migrantes) y 256 (en relación con los menores solicitantes de asilo).

16 La cursiva es nuestra. El Tratado de Lisboa, firmado el 13 de diciembre de 2007, entró en vigor el 1 de diciembre de 2009 (DO C 83, de 30 de marzo de 2010, pp. 1-388). El TFUE atribuye a la UE una competencia compartida en este ámbito (véase el art. 4.2.j). A pesar de que los discursos políticos de la Comisión, y también del Consejo, apuestan desde hace años por el denominado enfoque integral en materia de inmigración (esto es, por una política común que atienda todos los aspectos del fenómeno migratorio y no únicamente el securitario) y de que se han aprobado también un número importante de iniciativas en materia de "migración legal» (reagrupación familiar, residentes de larga duración, trabajadores cualificados, estudiantes e investigadores, etc.), la preocupación por mantener y fortalecer la seguridad de las fronteras y los instrumentos que permiten una lucha más eficaz contra los flujos irregulares sigue siendo, en nuestra opinión, prioritaria. La bibliografía sobre los desarrollos de la política común de inmigración en la UE es ingente. A título de ejemplo, pueden verse: Pablo Antonio FERNÁNDEZ SÁNCHEZ, Derecho comunitario de la 
sigue siendo competencia de los Estados miembros la adopción de las normas relativas al estatuto jurídico de los inmigrantes en situación administrativa irregular. En definitiva, la «inmigración irregular» se concibe en el seno de la UE como un fenómeno contra el cual hay que luchar y se ha buscado y fortalecido la cooperación entre los Estados con ese propósito ${ }^{17}$. Se ha buscado, en particular, la adopción de normas y medidas comunes tendentes a perfeccionar el control de fronteras, sancionar (administrativamente) las migraciones irregulares y asegurar el retorno a su país de origen de todos los inmigrantes que se encuentran en situación administrativa irregular.

Sin embargo, la Carta de Derechos Fundamentales de la UE ${ }^{18}$ insta a la protección de muchos de sus derechos relativos a la dignidad, la libertad, la igualdad, la solidaridad y la justicia a «toda persona». Cabría deducir de ello que, no distinguiendo la Carta respecto del disfrute de esos derechos entre nacionales de la UE/terceros países, ni, en relación con estos últimos, entre inmigrantes en situación administrativa regular o irregular, aquellos deben garantizarse a todos, independientemente de su situación migratoria ${ }^{19}$. Del mismo modo, el Protocolo núm. 12 al Convenio Europeo para la protección de los derechos humanos y las libertades fundamentales (CEDH), firmado en 2000 y en vigor desde 2005, incorpora una prohibición general de discriminación al establecer que «el goce de todos los derechos reconocidos por la ley

inmigración, Atelier, Barcelona, 2006; Andrew GEDDES, Inmigration and European Integration: Towards Fortress Europe, Manchester University Press, Manchester, 2008, Elspeth GUILD, Immigration Law in the European Community, Kluwer, La Haya, 2013, Georgia PAPAGIANNI, Institutional and Policy Dynamics of EU Immigration Law, Martinus Nijhoff Publishers, Leiden, Boston, 2006, y Martin A. SCHAIN, "The State Strikes Back: Immigration Policy in the European Union», European Journal of International Law, vol. 20, núm. 1, 2009, pp. 93-109.

17 En realidad, tal y como se ha afirmado, «(t)he border control imperative has become a headline maker around the globe, and it is a vital domestic political issue in all prosperous Western states, and elsewhere as well», Catherine DAUVERGNE, Making People Illegal. What Globalization Means for Migration and Law, Cambridge University Press, Cambridge, 2008, p. 2. DO C 326, de 26 de octubre de 2002, pp. 391-407.

19 Por el contrario, determinadas disposiciones de la Carta restringen su ámbito de aplicación personal a los ciudadanos de la UE o a los residentes legales. Es el caso de los arts. 15 (acceso al mercado laboral), 34.2 (relativo a las prestaciones sociales y a las ventajas sociales) y 45 (libertad de circulación y residencia). Además, la Carta condiciona ciertos derechos y principios que están garantizados a toda persona a lo dispuesto en los Derechos y prácticas nacionales (así lo disponen, por ejemplo, los arts. 34 (seguridad social) y 35 (protección de la salud). 
han de ser asegurados sin discriminación alguna, en particular por razones de sexo, raza, color, lengua, religión, opiniones políticas o de otro carácter, origen nacional o social, pertenencia a una minoría nacional, fortuna, nacimiento o cualquier otra situación" y que nadie será discriminado por ninguno de esos motivos por una autoridad pública ${ }^{20}$. A diferencia del art. 14 del Convenio, el Protocolo incorpora un derecho autónomo a no ser discriminado ${ }^{21}$.

En este contexto, este trabajo tiene por objeto, en primer lugar, examinar de qué modo los órganos europeos de protección de derechos humanos (en particular el Tribunal de Justicia de la UE - TJUE_-, el Tribunal Europeo de Derechos Humanos - TEDH - y el Comité Europeo de Derechos Sociales $^{22}$ ) se han ocupado de la extensión de determinados derechos de carácter socio-económico a un colectivo determinado: el formado por los inmigrantes en situación administrativa irregular. En particular, el trabajo explorará cómo los conceptos de dignidad humana y vulnerabilidad han servido a estos órganos con ese propósito (II).

También, no podía ser de otra manera, los Tribunales Constitucionales de los Estados miembros se han enfrentado a esa misma cuestión. Sin ánimo de exhaustividad, se analizarán también en este trabajo algunas de las decisiones adoptadas en este sentido. Se trataría de analizar, en definitiva, si es posible hablar de un diálogo vertical ${ }^{23}$ en lo que hace al establecimiento

20 El Protocolo está disponible en http://www.conventions.coe.int/Treaty/Commun/QueVoulezVous.asp?NT=177\&CM=8\&DF=31/07/2015\&CL=ENG, (consultado por última vez el 17.10.2015).

21 De todos modos, tal y como señala el Informe explicativo, no serán contrarias al Protocolo aquellas diferencias de trato basadas en la nacionalidad que persigan un objetivo legítimo y cuando los medios empleados para alcanzarlo sean proporcionales: $\mathrm{cfr}$. el párrafo 19 del Informe explicativo, disponible en la siguiente dirección electrónica: http://www.coe.int/en/web/conventions/full-list/-/conventions/treaty/177 (consultado por última vez el 17.12.2015). Sobre el Protocolo véase: Urfan KHALIQ, «Protocol 12 to the European Convention on Human Rights: a step forward or a step too far?», Public Law, otoño, 2001, pp. 457-464.

22 En el caso de estos dos últimos (el TEDH y el Comité Europeo de Derechos Sociales) se ha hablado de «retroalimentación»: Luis JIMENA QUESADA, «Las sinergias entre el Tribunal Europeo de Derechos Humanos y el Comité Europeo de Derechos Sociales: reflexiones sobre relaciones institucionales, informales y humanas en homenaje a Josep Casadevall», en Luis LÓPEZ GUERRA et al. (coords.), El Tribunal Europeo de Derechos Humanos. Una visión desde dentro. En homenaje al Juez Josep Casadevall, Tirant lo Blanch, Valencia, 2015, p. 119-133, p. 121.

23 No nos ocuparemos, por tanto, de un fenómeno por lo demás interesante: el del diálogo horizontal entre jurisdicciones constitucionales. Sobre esta cuestión Véase: 
de un estándar mínimo de derechos socio-económicos de los inmigrantes en situación administrativa irregular en Europa ${ }^{24}$ (III). La última sección del trabajo (IV) ofrece algunas conclusiones. Nuestro propósito último es tratar de contribuir al debate sobre cómo los tribunales, internacionales y nacionales, y algunos otros órganos de los sistemas de protección internacional de derechos humanos (en nuestro caso, el Comité Europeo de Derechos Sociales) han logrado acercar los derechos humanos a las personas, independientemente de su nacionalidad y/o estatus administrativo ${ }^{25}$.

\section{LA PROTECCIÓN DE LA DIGNIDAD HUMANA Y FRENTE A LA VULNERABILIDAD COMO FUNDAMENTO DE LA EXTENSIÓN JURISPRUDENCIAL DE LOS DERECHOS SOCIALES A LOS INMIGRANTES EN SITUACIÓN ADMINISTRATIVA IRREGULAR}

\section{LA DIGNIDAD HUMANA COMO LÍMITE}

En general, ya se ha dicho, la acción política y normativa de la UE no ha alcanzado verdaderamente el estatuto jurídico de los nacionales de terceros países que se encuentran en situación administrativa irregular en su territorio $^{26}$. Con todo, pueden citarse algunas excepciones que se refieren a las víctimas de la trata de seres humanos y a los menores extranjeros no acompañados,

Didier MAUS, «Le recours aux précédents étrangers et le dialogue des cours constitutionnelles», Revue Française de Droit Constitutionnel, núm. 80, 2009, pp. 675-696 y Marcelo NEVES, Transconstitucionalismo, Editora WMF Martins Fontes, São Paulo, 2009, pp. 101 y ss.

Sobre la noción de «diálogo judicial» véase el reciente trabajo de María DÍAZ CREGO, «Diálogo judicial», Eunomía. Revista en Cultura de la Legalidad, núm. 9, 2015, pp. 289-299.

En este sentido, Ruth RUBIO-MARÍN, «Introduction: Human Rights and the Citizen/Non-citizen Distinction Revisited», en Ruth RUBIO-MARÍN (ed.), Human Rights and Immigration, Oxford University Press, Oxford, 2014, p. 7.

26 Algún autor ha calificado de difícil la relación entre «derechos» e «inmigración irregular»: Sergio CARRERA y Massimo MERLINO, Undocumented Migrants and Rights in the EU: Addressing the Gap between Social Science Research and Policy-making in the Stockholm Programme? CEPS, Bruselas, 2009, p. 1, disponible en la siguiente dirección electrónica: http://aei.pitt.edu/15103/1/Undocumented_Migrants_Zennstrom_Rpt_by_Carrera_Merlino_e-version.pdf (consultado por última vez el 17.10.2015). 
cuya situación sí ha sido particularizada, a los efectos que interesan a nuestro análisis, en determinados instrumentos del Derecho de la UE ${ }^{27}$. Por lo demás, se ha señalado ya suficientemente por parte de la doctrina y la sociedad civil que, en lo que hace a la política europea de lucha contra la inmigración irregular, el verdadero objetivo común ha sido durante décadas lograr, de un lado, frenar las llegadas irregulares y, de otro, el retorno de los inmigrantes que se encuentren en situación administrativa irregular y que, de acuerdo con las normas aplicables de Derecho internacional y europeo, no tengan derecho a permanecer en el territorio de la UE. Siendo esos los objetivos que se marcan los Estados miembros, no puede extrañar que el art. 79.2.b) del Tratado de TFUE otorgue competencia a las instituciones de la UE para legislar en materia de derechos de, únicamente, los nacionales de terceros países que sean residentes legales.

Debe tenerse en mente, desde luego, que está vigente un principio de Derecho internacional público según el cual los Estados pueden adoptar medidas en el ámbito del control de fronteras, lo que incluye la devolución de aquellos inmigrantes en situación administrativa irregular que no tengan derecho a permanecer en el país de destino. Ese derecho soberano del Estado, que prima sobre la pretensión del extranjero a permanecer en el país, ha sido afirmado reiteradamente por la Asamblea General de Naciones Unidas ${ }^{28}$ y, en el ámbito europeo, recogido por la jurisprudencia del TEDH desde su sentencia dictada en el asunto Abdulaziz, Cabales y Balkandani v. Reino Unido $(\text { Pleno })^{29}$. Creemos, sin embargo, que es posible constatar un incipiente, aunque no marginal, cambio en la actitud de las instituciones de la UE gracias al

27 La Directiva 2011/36/UE del Parlamento Europeo y del Consejo, de 5 abril de 2011, relativa a la prevención y lucha contra la trata de seres humanos y a la protección de las víctimas y por la que se sustituye la Decisión marco 2002/629/JAI del Consejo (DO L 101, de 15 de abril de 2011, pp. 1-11) requiere a los Estados miembros para que tomen medidas tendentes a asegurar la asistencia y el apoyo a las víctimas (art. 11). Por su parte, el Plan de Acción de la Comisión Europea sobre los Menores Extranjeros no Acompañados (COM (2010) 213 final, 6.5.2010) contempla la posibilidad de que el menor se integre en el país de destino, si ello es lo que conviene a su interés. En ese caso, se debería garantizar un estatuto jurídico, un acomodo adecuado y apoyo en el camino hacia la integración en la sociedad de acogida.

28 Véase por todas la Resolución 69/167, de 12 de febrero de 2015, A/RES/69/197, disponible en http://www.un.org/es/comun/docs/?symbol=A/RES/69/167, (consultado por última vez el 17.10.2015).

29 Sentencia 28 de mayo de 1985, núm. 9214/80, 9473/81 y 9474/81, Series A núm. 94. 
protagonismo que han ganado las nociones de «vulnerabilidad» $\mathrm{y}$ «dignidad humana $»^{30}$.

De este modo, la dignidad humana emerge como «el más fundamental de los derechos ${ }^{31}$ tanto en la Carta de Derechos Fundamentales de la UE, cuyo art. primero anuncia que la misma es inviolable y que será respetada y protegida, como en la jurisprudencia del TJUE. Y sirve, en sede judicial, para fundamentar la protección tanto de los derechos sociales de los inmigrantes en situación administrativa irregular como sus derechos procesales (i.e., el derecho a ser oído y el derecho a no ser retornado en violación del principio de no devolución) ${ }^{32}$. Resulta particularmente relevante en este sentido una línea jurisprudencial que ha interpretado el alcance de las obligaciones y medidas previstas en la denominada Directiva de retorno ${ }^{33}$, recurriendo al concepto de "dignidad humana» como parámetro de validez de las mismas.

30 Véase al respecto los estudios incluidos en Francesca IPPOLITO y Sara IGLESIAS SÁNCHEZ, The Protection of Vulnerable Groups. The European Human Rights Framework, Hart Publishing, Oxford, 2015.

31 Se ha tomado la expresión de las Conclusiones del abogado general Jacobs adoptadas el 14 de junio de 2001 en el asunto Reino de los Paises Bajos c. Parlamento Europeo y Consejo de la Unión Europea, C-377/98, EU:C:2001:329, punto 197. Tal y como nos recuerda RIGAUX, la dignidad humana aparece vinculada a los derechos fundamentales y a la necesidad de su protección en buena parte de los teóricos que han elaborado la doctrina filosófica de los derechos fundamentales: François RIGAUX, «Les fondements philosophiques des droits de l'homme», Revue Trimestrielle des Droits de L’homme, núm. 70, 2007, pp. 307-349.

32 Véanse, de un lado, las sentencias del Tribunal de Justicia dictadas en los asuntos Zakaria, C-23/12, EU:C:2013:24, apdo. 40, y Mukarubega, C-166/13, EU:C:2014:2336, apdo. 39, y, de otro, El Dridi, C-61/11 PPU, EU:C:2011:268, apdo. 31; Arslan, C-534/11, EU:C:2013:343, apdo. 42; y Pham, C-474/13, EU:C:2014:2096, apdo. 20.

33 Directiva 2008/115/CE del Parlamento Europeo y del Consejo, de 16 de diciembre de 2008, relativa a normas y procedimientos comunes en los Estados miembros para el retorno de los nacionales de terceros países en situación irregular (DO L 348, de 24 de diciembre de 2008, pp. 98-107). Véase sobre la Directiva: Anneliese BALDACCINI, «The Return and Removal of Irregular Migrants under EU Law: An Analysis of the Return Directive», European Journal of Migration and Law, vol. 11, 2009, p. 1-17 Teresa FAJARDO DEL CASTILLO, «La Directiva sobre el retorno de los inmigrantes en situación irregular", Revista de Derecho Comunitario Europeo, núm. 33, 2009, pp. 453-499, y Francesco MARTUCCI, "La Directive "retour": la politique européenne d'immigration face à ses paradoxes», Revue Trimestrielle de Droit Européen, vol. 45, núm. 1, pp. 47-67. 
Aunque, en general, el TJUE no ha aludido expresamente a la Carta de Derechos Fundamentales, prefiriendo limitar sus argumentos a la (in)compatibilidad de las medidas nacionales con la finalidad y el texto de la Directiva, la Carta y su art. 1 están indirectamente incorporados al razonamiento del Tribunal. El mismo ha mantenido, en efecto, que el propósito de la Directiva 2008/115 es el establecimiento de «una política eficaz de expulsión y repatriación, basada en normas comunes, para que las personas afectadas sean retornadas humanamente y respetando plenamente sus derechos humanos y su dignidad ${ }^{34} \mathrm{y}$ ha reiterado que sus disposiciones deben interpretarse, como establece su segundo considerando, de tal modo que los derechos de las personas afectadas por las mismas no se vean conculcados.

Incluso más significativa en este sentido resulta la sentencia dictada en el asunto Moussa Abdida ${ }^{35}$, en la que el TJUE se basó implícitamente en el art. 1 de la Carta de Derechos Fundamentales de la UE para garantizar la protección de un inmigrante en situación administrativa irregular que estaba pendiente de expulsión más allá de lo que cabía deducir de la literalidad del Derecho derivado (en este caso, la Directiva de retorno). El señor Abdida era un nacional nigeriano que había presentado una solicitud de autorización de residencia a las autoridades belgas que fundaba en el hecho de padecer una enfermedad particularmente grave. Aunque su solicitud fue inicialmente aceptada y él recibió asistencia social, dos años después fue rechazada sobre la base de que en su país de origen era posible proporcionarle asistencia médica adecuada para esa enfermedad. Consecuentemente, la decisión le fue notificada, junto con la orden de abandonar Bélgica. Durante el tiempo en el que el recurso de apelación que presentó contra esa decisión estuvo pendiente de resolución, el apelante no recibió asistencia social. Y ello porque en el Estado miembro la misma solo se garantizaba en el marco de aquellos recursos de apelación que tenían efectos suspensivos. Y ese no era el caso del recurso interpuesto por el señor Abdida.

En su respuesta, el TJUE afirmó la prohibición de retorno a partir de la interpretación del art. 5 de la Directiva, de acuerdo con lo establecido por el art. 19.2 de la Carta de Derechos Fundamentales de la UE ${ }^{36}$. Así, el TJUE determinó

34 Cfr. las sentencias del TJUE dictadas en los asuntos El Dridi, apdo. 3; Arslan, apdo. 42; asunto Mahdi, C-146/14 PPU, EU:C:2015:298, apdo. 38; Pham, apdo. 20; y Mukarubega, apdo. 39.

35 C-562/13, EU:C:2014:2453.

36 De lo que cabe deducir que la devolución de un nacional de un tercer país aquejado de una enfermedad grave a un país en el que no existieran los tratamientos adecuados podría infringir en ciertos casos el art. 5 de la Directiva 2008/115. El apdo. c) de este art. dispone que cuando apliquen la Directiva, los Estados miembros deberán tener debidamente en cuenta el estado de salud del nacional del tercer país que vaya a ser 
que el recurso contra la decisión de retorno debía tener efectos suspensivos, lo que le llevó a considerar favorablemente la solicitud del Sr. Abdida de recibir asistencia sanitaria durante el tiempo de resolución del mismo, una prestación que no se menciona en el art. 14 de la Directiva de retorno. Así, partiendo de la premisa recogida en el preámbulo de la Directiva, según la cual durante el tiempo en el que esté pendiente la decisión de retorno, las «condiciones básicas de subsistencia deberán definirse de acuerdo con la legislación nacional», el Tribunal estableció que dicha legislación debe ser compatible con los requisitos establecidos por la Directiva. Del mismo modo, mantuvo que la interpretación de cualesquiera disposiciones de la misma debía hacerse, «con pleno respeto a los derechos fundamentales y la dignidad de la persona concernida ${ }^{37}$. Consecuentemente, y de acuerdo con el TJUE, el derecho a recibir asistencia sanitaria podría quedar privado de efecto real si no se acompañara de la cobertura, en la medida de lo posible, de las necesidades básicas del nacional interesado de un tercer país. Sin embargo, corresponde a los Estados miembros determinar la forma que deba tener esa cobertura.

\section{LA VULNERABILIDAD COMO FUNDAMENTO}

Hemos tratado de mostrar en el epígrafe anterior cómo la protección o garantía de la dignidad del individuo, en este caso migrante en situación ad-

retornado. Por su parte, el art. 19.2 de la Carta de Derechos Fundamentales de la UE consagra, como es sabido, el principio de non-refoulement. El Tribunal hace repetidas referencias a la jurisprudencia del TEDH (véase, por ejemplo, el apdo. 42 de la sentencia) a la que nos referiremos más adelante.

37 Véase la sentencia del TJUE dictada en el asunto Abdida, párrafo 42. Más allá fue el abogado general Bot en sus Conclusiones, presentadas el 4 de septiembre de 2014 y aún no publicadas en la recopilación oficial. En su opinión, la satisfacción de las necesidades básicas de cualquier individuo es un derecho esencial que no puede hacerse depender del estatuto jurídico del interesado. El TJUE ya se ha pronunciado sobre el alcance de la obligación de los Estados de asegurar condiciones de acogida que garanticen un nivel de vida digno a los solicitantes de asilo (nos referimos, en concreto, a las sentencias del Tribunal de Justicia dictadas en los asuntos Saciri y otros, C-79/13, EU:C:2014:103, apdos. 42 y 50, y Cimade y GISTI, C-179/11, EU:C:2012:594, apdos. 42-45 y 56). El abogado general Bot alude directamente a la necesidad de respetar la dignidad humana y los derechos a la vida, la integridad y la salud reconocidos respectivamente en los arts. 1, 2, 3 y 35 de la Carta de Derechos Fundamentales de la UE, así como a la prohibición de tratos inhumanos o degradantes enunciada en el art. 4, para reconocer a un nacional de un tercer país en situación irregular y cuya expulsión se ha suspendido, que cae bajo el ámbito de aplicación de la Directiva del retorno, el derecho a la cobertura de sus necesidades básicas en espera de la resolución sobre su recurso. 
ministrativa irregular, marca en la jurisprudencia del TJUE un límite relevante a la hora de interpretar el alcance del Derecho de la UE. En particular, en la jurisprudencia analizada, de la Directiva de retorno. No traspasar dicho límite, lo que significaría colocar al inmigrante en una situación "indigna», puede exigir la prestación de determinados derechos de naturaleza socio-económica. Y ello está directamente relacionado con la idea de que ese colectivo, el formado por inmigrantes en situación administrativa irregular, se encuentra en situación de especial vulnerabilidad, siendo posible concebir esa condición administrativa como una forma de vulnerabilidad impuesta por el Estado ${ }^{38}$. También el TJUE se ha valido de esta noción, por tanto, para mejorar la protección social de los migrantes. De momento, eso sí, únicamente en los casos en los que dicha vulnerabilidad se superpone, de un lado, a la vulnerabilidad inherente a los menores, $y$, de otro, a un colectivo que si bien no se encuentra en situación administrativa irregular, no cuenta todavía con una decisión que aclare de modo estable su estatuto jurídico: el de los solicitantes de asilo ${ }^{39}$.

38 Sara IGLESIAS SÁNCHEZ, "Irregular Migrants in Europe: Deprivation of Status as a Type of State-Imposed Vulnerability», en IPPOLITO e IGLESIAS SÁNCHEZ, op. cit., nota 30, pp. 429-451, p. 429. En un sentido semejante, RODERA RANZ afirma que "(e)l legislador [interno] se sirve de la construcción legal de un estatuto para discriminar en derechos a personas por el solo hecho de encontrarse en situación administrativa irregular»: Susana RODERA RANZ, La protección internacional de la persona migrante en situación irregular: estudio de la Convención Internacional sobre la Protección de los Derechos de Todos los Trabajadores Migratorios y de sus Familiares, tesis Doctoral inédita, Universidad de Zaragoza, 2014, disponible en la siguiente dirección electrónica: https://zaguan.unizar.es/record/13294/files/TESIS-2014-002.pdf (consultado por última vez el 17.10.2015), pp. 480-481.

39 Entendiendo por tal al nacional de un tercer país o apátrida que haya presentado una solicitud [de asilo] sobre la cual todavía no se haya dictado una resolución definitiva: cfr. el art. 2.b) de la Directiva 2013/33/UE del Parlamento Europeo y del Consejo, de 26 de junio de 2013, por la que se aprueban normas para la acogida de los solicitantes de protección internacional (texto refundido) (DO L 180, de 29 de junio de 2013, pp. 96-116). Un estudio exhaustivo de la jurisprudencia del TEDH que se ha ocupado de la protección de los demandantes de asilo, al que identifica como grupo vulnerable, puede verse en: Silvia MORGADES GIL, «La protección de los demandantes de asilo por razón de su vulnerabilidad especial en la jurisprudencia del Tribunal Europeo de Derechos Humanos", Revista de Derecho Comunitario Europeo, núm. 37, 2010, pp. 801-842. El examen de la práctica revela que, si bien los demandantes de asilo no son siempre refugiados per se, en muchas ocasiones - como en el caso de los migrantes que tratan de acceder irregularmente al territorio- el proyecto migratorio se ha visto forzado por la pobreza y/o una situación de violación generalizada de derechos humanos. Debe tenerse en cuenta, igualmente, que un número 
Creemos que resulta posible constatar esta afirmación, en primer lugar, si analizamos determinados discursos político-institucionales. En relación, por ejemplo, con los menores no acompañados, el Plan de la Comisión Europea para 2010-2014 ${ }^{40}$, aunque mantiene el objetivo central de ayudar a los Estados miembros a adoptar medidas para facilitar el retorno del alto número de menores no acompañados que no requieren de protección internacional, subraya que «la solución no puede limitarse al retorno porque la cuestión es mucho más compleja y multidimensional, y existen límites claros a la libertad de acción de los Estados miembros para tratar a los menores no acompañados» ${ }^{41}$. Establece también que la legislación y las políticas de la UE no contemplan la situación de los menores que no pueden ser retornados, siendo la decisión de proporcionarles un permiso de residencia por razones humanitarias o de otra índole competencia de los Derechos internos. No obstante, en los casos en que el retorno no sea posible o en los que se considere que el interés superior del menor es la integración en el país de residencia, deberá concederse un estatuto que les reconozca como mínimo los mismos derechos y la protección de que disfrutaban anteriormente, y se les buscará un alojamiento idóneo. Además, los menores deberían recibir ayuda en el proceso de su integración en la sociedad de acogida.

En el mismo sentido, en su comunicación titulada «Una Política Común de Emigración para Europa: principios, medidas e instrumentos» ${ }^{42}$, la Comisión Europea mantuvo que la UE y sus Estados miembros debían asegurarse de que los nacionales de terceros países que residen ilegalmente en el territorio de la Unión tienen acceso a servicios esenciales para garantizar el respeto de los derechos humanos fundamentales, entre ellos la educación de los niños y la atención sanitaria básica, lo que identificó como un elemento necesario de la política en materia de lucha contra la inmigración irregular y la trata de seres humanos. Cabe citar igualmente la Resolución del Parlamento Europeo, de 8 de marzo de 2011, sobre la reducción de las desigualdades en salud en la $\mathrm{UE}^{43}$, en la que se pide a los Estados miembros «que garanticen que los grupos más

indeterminado de migrantes irregulares, para tratar de paralizar su devolución, y aun a cosa de restar oportunidades a los refugiados, solicitan asilo, sobrecargando así los procedimientos de determinación del estatuto de refugiado en los Estados miembros. Por último, algunos solicitantes de asilo cuya solicitud es desestimada, vienen a coincidir con algunos inmigrantes en situación administrativa irregular en la categoría de «inexpulsables».

40 Véase supra nota 27.

41 Cfr. la introducción de la Comunicación.

42 COM (2008) 359 Final, 17.6.2008.

43 2010/2089 (INI). 
vulnerables, incluidos los migrantes indocumentados, tienen derecho a un acceso equitativo a la asistencia sanitaria y disfrutan de él en la práctica; pide a los Estados miembros que examinen la viabilidad de apoyar la asistencia sanitaria para los migrantes en situación irregular, a través de una definición, basada en principios comunes, de los elementos básicos de dicha asistencia tal y como se encuentran definidos en sus respectivas legislaciones nacionales ${ }^{44}$.

Las mismas conclusiones se extraen del análisis de la jurisprudencia del TJUE. En su sentencia dictada en el asunto Cimade y GISTI, ya citada aquír5, el Tribunal declaró que las normas mínimas para la acogida de los solicitantes de asilo, y la exigencia de que sea respetada la dignidad humana del individuo, se aplican no solo a los solicitantes de asilo que se encuentren en el territorio del Estado miembro responsable en espera de la decisión de este sobre su solicitud de asilo, sino también con respecto a los solicitantes de asilo que estén a la espera de la determinación del Estado miembro responsable de la solicitud. Esto es, incluso a un solicitante de asilo que decide requerir a otro Estado miembro para que se haga cargo de él o lo readmita como Estado miembro responsable del examen de su solicitud. El Tribunal rechazó así el argumento de que las normas mínimas para la acogida de los solicitantes de asilo no son aplicables a aquellos afectados por el procedimiento de determinación del Estado responsable debido a que este procedimiento es rápido ${ }^{46}$. El fundamento para descartar la posibilidad de que un solicitante de asilo sea privado, aunque sea de manera temporal, tras la presentación de la solicitud de asilo y antes de su traslado efectivo al Estado miembro responsable, de la protección de las normas mínimas establecidas por dicha Directiva, lo constituye precisamente lo requerido por el art. 1 de la Carta, según el cual, como ya se ha dicho aquí, la dignidad humana será respetada y protegida ${ }^{47}$.

Por su parte, lo que fue determinante para el Tribunal en su sentencia dictada en el asunto SACIRI y otros $^{48}$ fue la situación de vulnerabilidad del menor que estaba en situación administrativa irregular y había presentado una solicitud de asilo. El Tribunal recalcó que el periodo durante el cual deben asegurarse las condiciones materiales de acogida comienza cuando el individuo solicita asilo, tal y como se deduce del tenor literal, el esquema general y el

\footnotetext{
44 Véase el apdo. 5 de la Resolución.

45 Véase supra nota 37.

46 Véase los apdos. 43 y 44 de la sentencia.

47 Ibid. apdo. 56.

48 Véase supra nota 37.
} 
propósito de la Directiva 2003/9/CE. También en el caso de inmigrantes en situación irregular que presenten una solicitud de asilo ${ }^{49}$.

Además, el Tribunal también dedujo de la Directiva que la ayuda financiera que se proporcione debe ser suficiente para garantizar atención sanitaria y un nivel de vida digno y adecuado que permita subsistir a los solicitantes de asilo, debiendo los Estados miembros adaptar las condiciones de recepción a la situación de aquellas personas con necesidades especiales. Y ello con el fin, en particular, de preservar la unidad familiar y asegurar el interés superior del menor (lo que incluye que el menor sea alojado con sus padres). En el caso de que la vivienda no sea proporcionada en especie, la ayuda financiera debe permitir a los solicitantes de asilo obtenerla, si fuese necesario, en el mercado privado de alquiler, sin que ello signifique que deba dejarse a los solicitantes de asilo la elección de un alojamiento según su conveniencia personal ${ }^{50}$.

\section{LA COMBINACIÓN DE LA DIGNIDAD HUMANA Y LA NOCIÓN DE VULNERABILIDAD}

También en el ámbito del Consejo de Europa está presente la alusión a la dignidad de los inmigrantes en situación administrativa irregular y la necesidad de asegurar sus derechos sociales. Un ejemplo significativo, en este sentido, lo constituye la Resolución de su Asamblea Parlamentaria de 4 de mayo de 2006, que enfatiza la necesidad de clarificar algunas cuestiones especialmente controvertidas y de proporcionar estándares comunes en este ámbito ${ }^{51}$. Se afirma en la misma, de un lado, que debe ser tenido en cuenta, como punto de partida, que los instrumentos internacionales de derechos humanos se aplican a todos los individuos, con independencia de su nacionalidad o estatus administrativo. Y, de otro, que los inmigrantes en situación administrativa irregular deben tener garantizados determinados derechos humanos mínimos, de tal modo que se les permita vivir de un modo humano y digno. Entre estos derechos se incluyen algunos derechos básicos civiles y políticos y, también, sociales y económicos ${ }^{52}$.

Con todo, lo verdaderamente relevante en el sistema del Consejo de Europa, por lo que hace a las cuestiones que se analizan en este trabajo, es que la combinación de las noción de dignidad con la de vulnerabilidad ha servido a al-

49 Véase el apdo. 33 de la sentencia.

50 Ibíd, apdo. 43.

51 Resolución 1509 (2006), de 27 de junio de 2006, relativa a los derechos humanos de los migrantes irregulares, PACE Doc. 10924, disponible en http://assembly.coe.int (consultado por última vez el 17.10.2015).

52 Cfr. el apdo. 13 de la Resolución. 
gunos órganos del sistema —el Comité de Derechos Sociales y el TEDH— para perfilar el alcance de dichos derechos. De modo análogo, ambas nociones se han combinado en instrumentos de soft law. Es el caso de la Declaración adoptada por la VII Conferencia de Ministros del Consejo de Europa responsables de Inmigración, celebrada en Helsinki en septiembre de 2002. En la misma, los ministros reclamaban que se prestase atención a aquellas cuestiones que afectaban a la dignidad humana, incluyendo las relativas al disfrute efectivo de un estándar mínimo de derechos para las personas necesitadas de protección. Los gobiernos parecían reconocer, así, que la marginalización y exclusión de los grupos vulnerables en la sociedad, con independencia de su estatus administrativo, eran situaciones que debían ser paliadas a través de la acción positiva del Estado.

En particular, el Comité Europeo de Derechos Sociales ha combinado la noción de dignidad humana con la de especial vulnerabilidad de los hijos de una familia en situación administrativa irregular para extender el ámbito de aplicación personal de la Carta Social Europea (Revisada) $)^{53}$ en lo que hace al acceso a un nivel de salud suficiente ${ }^{54} \mathrm{y}$ a asistencia médica ${ }^{55}$, así como el derecho a un lugar de alojamiento (tras adoptar una aproximación minimalista que rechazó el derecho a la vivienda). Mientras que en relación con los dos primeros derechos mencionados el Comité consideró que los derechos sociales eran "prerrequisitos» de la dignidad humana, en relación con el último la dignidad fue igualmente el fundamento de la citada aproximación minimalista. De este modo, ha reconocido que los inmigrantes irregulares no tienen derecho a una vivienda adecuada sobre la base del art. 31.1 de la Carta Social Europea (Revisada) ${ }^{56}$, sino que únicamente tienen derecho a un alojamiento sobre la base del art. $31.2^{57}$. Dicho alojamiento deberá contar

53 Carta Social Europea (Revisada), de 3 de mayo de 1996, CETS núm. 163, disponible en http://www.coe.int/en/web/conventions/full-list/-/conventions/treaty/163 (consultado por última vez el 17.10.2015).

54 Véanse las decisiones adoptadas en los asuntos Federación Internacional de Ligas de Derechos Humanos (FIDH) c. Francia, Reclamación núm. 14/2003, Decisión sobre el fondo de 7 de septiembre de 2004, apdo. 32, y Defence for Children International (DCI) c. Bélgica, Reclamación número 69/2011, Decisión sobre el fondo de 23 de octubre de 2012, apdo. 102. Todas las decisiones del Comité Europeo de Derechos Sociales citadas a lo largo del trabajo están disponibles en http://hudoc.esc.coe.int/ eng\#, (consultado por última vez el 17.10.2015). Ibid.

El art. 31.1 establece que «(p)ara garantizar el acceso efectivo del derecho a la vivien$\mathrm{da}$, las Partes se comprometen a adoptar medidas destinadas a favorecer el acceso a la vivienda de un nivel suficiente».

Este apdo. segundo del art. 31 señala que los Estados parte deberán también adoptar medidas destinadas «a prevenir y paliar la situación de carencia de hogar con vistas a 
con las condiciones sanitarias, de seguridad y de higiene adecuadas y deberá disponer de los servicios básicos, de tal modo que quede asegurado el respeto a la dignidad de las personas alojadas ${ }^{58}$. Aun así, el alojamiento es por naturaleza temporal y no reúne las condiciones de privacidad, respeto a la vida familiar e idoneidad de la vivienda permanente convencional ${ }^{59}$.

De acuerdo con esas consideraciones, en el asunto DCI c. Holanda el Comité explicó que, aun sin derecho a una vivienda adecuada, las personas no deben verse privadas de aquellos cuidados básicos sin los cuales las condiciones de vida se vuelven intolerables. Y requirió a los Estados parte a proporcionar un alojamiento adecuado a los menores en situación administrativa irregular mientras se encontrasen bajo su jurisdicción. Cualquier otra solución supondría, en opinión del Comité, vulnerar la dignidad humana y no tomar debidamente en cuenta la situación de particular vulnerabilidad de los niños ${ }^{60}$.

De modo análogo, en 2014, el Comité declaró que debe proporcionarse también alojamiento a los adultos en situación administrativa irregular, incluso cuando han sido requeridos para abandonar el territorio y por lo tanto no necesitarán una acomodación a largo plazo en una vivienda permanente ${ }^{61}$. El Comité se refirió en este caso a su doctrina relativa al art. 13.4 de la Carta ${ }^{62}$ y reiteró que el derecho a un alojamiento está íntimamente conectado con la dignidad humana de toda persona, independientemente de su estatus administrativo ${ }^{63}$. Consideró que, sobre la base de la violación del mencionado art. 13.4, había habido también violación del art. $31.2^{64}$.

eliminar progresivamente dicha situación» (las cursivas son nuestras).

58 Asunto Defence for Children Internacional (DCI) c. Holanda, Reclamación núm. 47/2008, Decisión sobre el fondo de 20 de octubre de 2009, apdo. 62.

59

60 Asuntos DCI c. Holanda, ya citado, párrafo 47, y DCI c. Bélgica, ya citado, párrafo 136.

61 El asunto se refería tanto a inmigrantes en situación administrativa irregular como a solicitantes de asilo cuyas solicitudes habían sido inadmitidas.

62 Que determina que los Estados partes deberán aplicar los apdos. 1, 2 y 3 del art. 13 (que protege el derecho a la asistencia social y médica) «en condiciones de igualdad con sus nacionales, a los de las restantes Partes que se encuentren legalmente en su territorio, conforme a las obligaciones derivadas del Convenio Europeo de Asistencia Social y Médica, firmado en París el 11 de diciembre de 1953».

63 Véase el apdo. 136 de la decisión dictada en el asunto Conference of European Churches c. Holanda, reclamación núm. 90/2013, Decisión sobre el Fondo de 1 de julio de 2014.

64 Ibid. apdo. 144. 
Por su parte, el TEDH ha reconocido progresivamente respecto de estos grupos vulnerables - aunque en mayor medida respecto de los solicitantes de asilo que de los niños - que la ausencia de alojamiento y el hecho de que las necesidades básicas no sean aseguradas juegan un papel decisivo a la hora de concluir si el demandante ha sufrido un trato humillante contrario al art. 3 del Convenio ${ }^{65}$. En cualquier caso, no puede dejar de ponerse de manifiesto aquí que la jurisprudencia posterior del TEDH ha consolidado y, al tiempo, matizado, lo decidido en el asunto M.S.S. v. Bélgica y Grecia, sobre todo en lo que hace a la determinación de la situación de especial vulnerabilidad de las víctimas (actuales o potenciales) de violaciones de derechos protegidos por el $\mathrm{CEDH}^{66}$. El TEDH determinó en este caso que la devolución por parte de las autoridades suizas de los demandantes (una familia de afganos) a Italia violaría el art. 3 del CEDH si las primeras no se asegurasen antes de que la familia iba a permanecer unida en un lugar adaptado a las necesidades de los hijos menores mientras se tramitaba su solicitud de asilo. Resulta muy interesante en este caso que el TEDH se refiere en su decisión a la doctrina de las «deficiencias sistemáticas» enunciada por el TJUE en su sentencia N.S. ${ }^{67}$. El TJUE declaró en esa sentencia que "en el supuesto de que hubiera razones para temer fundadamente que existen deficiencias sistemáticas en el procedimiento de asilo y en las condiciones de acogida de los solicitantes de asilo en el Estado miembro responsable que implican un trato inhumano o degradante, en el sentido del art. 4 de la Carta [de Derechos Fundamentales de la UE], de los solicitantes de asilo trasladados al territorio de ese Estado miembro, ese traslado sería incompatible con dicha disposición ${ }^{68}$. En su sentencia, el TEDH concluye que, aun no siendo ese el caso de Italia, la mera posibilidad de que los demandantes

65 M.S.S. v. Bélgica y Grecia (Gran Sala), núm. 30696/09, 21 de enero de 2011, ECRH 2011-I, apdo. 263. Sobre esta sentencia puede verse: Violeta MORENO-LAX, «Dismantling the Dublin System: M.S.S. v. Belgium and Greece», European Journal of Migration and Law, vol. 14, núm. 1, 2012, pp. 1-31, y Silvia MORGADES GIL, «TEDH - Sentencia de 21.01.2011 (Gran Sala), M.S.S. c. Bélgica y Grecia, 30696/09 "Arts. 3 y 13 CEDH Prohibición de tortura y penas o tratos inhumanos o degradantes. Reglamento (CE) Núm. 343/2003 de determinación del Estado responsable del examen de una solicitud de asilo (Dublín II)» - El funcionamiento efectivo de la política europea de asilo ante la garantía del derecho a no sufrir tratos inhumanos o degradantes», Revista de Derecho Comunitario Europeo, núm. 41, 2012, pp. 183-204.

66 Véase, en este sentido la sentencia de 4 de noviembre de 2014 (Gran Sala), Tarakhel c. Suiza, núm. 29217/12, apdos. 100-122.

67 Sentencia TJUE N.S, C-411/10 y C-493/10, EU:C:2011:865.

68 Ibid., apdo. 80. 
pudiesen ser separados y/o alojados en un lugar poco adecuado era suficiente para afirmar la violación del art. 3 del CEDH. El Tribunal fundamenta su decisión, por tanto, en la situación de vulnerabilidad agravada en la que se encuentran los menores, concebidos así como una categoría especial de sujetos vulnerables ${ }^{69}$.

El TEDH ha admitido también, en relación con la categoría de inmigrante en situación administrativa irregular, que su expulsión puede, en determinadas circunstancias, constituir un trato inhumanúm. Ello será así, inter alia, cuando el demandante no tenga asegurado, en el Estado de destino, un nivel mínimo de alimento, alojamiento o apoyo social ${ }^{70}$. De este modo, el TEDH ha admitido implícitamente que esa asistencia básica debe proporcionarse en el Estado del que va a ser expulsado el inmigrante ${ }^{71}$, aunque aquel no podrá, sobre la base del art. 3, sustentar un derecho a permanecer en el mismo con el fin de continuar recibiendo esa asistencia. En otro orden de cosas, el TEDH ha considerado que las condiciones de trabajo y de vida a las que fue sometida una empleada doméstica, nacional de Togo, que permaneció durante años en situación administrativa irregular y fue explotada laboralmente por sucesivos empleadores, eran incompatibles con la dignidad humana y suponía un trato contrario al art. 4 del CEDH, que prohíbe la esclavitud, la servidumbre y el trabajo forzado ${ }^{72}$.

69 Véase, al respecto Francesca IPPOLITO, «A European Judicial Dialogue on Refugee Rights?», Human Rights and International Legal Discourse, núm. 2, 2015, pp. 184212, p. 202.

70 Sentencia de 27 de mayo de 2008 (Gran Sala), N. v. Reino Unido, núm. 26565/05, ECHR 2008-III apdo. 42.

71 Véase la reciente sentencia de 7 de julio de 2015, V.M. y otros v. Bélgica, núm. $60125 / 11$, aún no publicada en la recopilación oficial, en la que el TEDH consideró que Bélgica había violado el art. 3 del CEDH debido a que las autoridades no habían tenido en cuenta la situación de vulnerabilidad en la que se encontraban los demandantes, solicitantes de asilo y menores, que habían sido expuestos a condiciones de extrema pobreza durante cuatro semanas, durante las cuales se vieron obligados a dormir en la calle sin que sus necesidades básicas quedasen cubiertas. El Tribunal consideró en particular que las autoridades belgas habían vulnerado su obligación de no exponer a los demandantes a un trato degradante, a pesar de que era sabido que la red de acogida para solicitantes de asilo estaba, en la época, en plena crisis (la denominada "crisis de la recepción» entre 2008 y 2013).

72 Sentencia de 26 de julio de 2005, Siliadin v. Francia, núm. 73316/01, ECHR 2005VII, apdo. 142. Sobre esta sentencia véase, por todos: Andrea NICHOLSON, «Reflections on Siliadin v. France: Slavery and Legal Definition», International Journal of Human Rights, vol. 14, núm. 5, 2010, pp. 705-720, 
También debe tenerse en cuenta que la Comisión Europea de Derechos Humanos ha reconocido la existencia de un vínculo estrecho entre el derecho a la vida familiar y el derecho a la vivienda adecuada ${ }^{73}$. De acuerdo con su doctrina, el art. 8 del Convenio puede fundamentar la obligación de evitar "condiciones de vida intolerables», una obligación que, dado el ámbito de aplicación personal del Convenio, incumbe a los Estados respecto de cualquier persona que esté bajo su jurisdicción, lo que incluye a los inmigrantes en situación administrativa irregular. Un argumento adicional en el mismo sentido, basado en la noción de especial vulnerabilidad, puede encontrarse en el asunto Yordanova y otros c. Bulgaria, en el que el TEDH determinó que «la obligación de proporcionar alojamiento a individuos en situación de particular vulnerabilidad puede derivarse, en casos excepcionales, del art. 8 del Convenio» ${ }^{74}$.

Fue también la noción de vulnerabilidad, en este caso inherente al menor, junto con su derecho humano a la dignidad, la base de la doctrina originaria del Comité Europeo de Derechos Sociales relativa a la ampliación del ámbito de aplicación personal de la Carta Social Europea a los inmigrantes en situación administrativa irregular, en relación ahora con el derecho a la salud. En particular, y tal y como se ha dicho ya, el Comité ha considerado que el acceso a un nivel de salud suficiente ${ }^{75}$ y a asistencia médica ${ }^{76}$, son prerrequisitos para la preservación de la dignidad humana ${ }^{77}$. Así, si bien para el Comité debe ase-

73 Informe de la Comisión de 7 de diciembre de 1978, Guzzardi v. Italia, núm. 7367/76. Esta posición ha sido reafirmada por el Tribunal en relación con un caso de contaminación medioambiental severa en su sentencia de 9 de diciembre de 1994, López Ostra c. España, núm. 16798/90, apdo. 51, y de 19 de febrero de 1998, Guerra y Otros c. Italia, núm. 14967/89, apdo. 60. Véase al respecto: Scott LECKIE, «The Human Right to Adequate Housing», en Asbjørn AIDE et al. (eds.), Economic, Social and Cultural Rights: A Textbook, Martinus Nijhoff, Dordrecht, 2001, pp. 149-168.

74 Sentencia de 24 de abril de 2012, núm. 25446/06, apdo. 130.

75 FIDH c. Francia, párrafo 32, y DCI c. Bélgica, párrafo102.

76 DCI c. Bélgica, párrafo 122.

77 FIDH c. Francia, párrafos 31-31. De nuevo vuelve a ser necesaria una referencia a la jurisprudencia de la CtIADH. En Vélez Loor vs. Panamá (Véase supra nota 13) la Corte se pronunció sobre el alcance del derecho del demandante (un inmigrante irregular privado de libertad) a recibir asistencia médica. Para la Corte, el hecho de que el demandante no la recibiese hizo que el sufrimiento inherente a la privación de libertad excediese de lo inevitable, lo que implicó una violación de la obligación de no infligir penas o tratos crueles, inhumanos y degradantes (apdo. 199) y la lesión de su dignidad (apdos. 225 y 227). Además, la Corte tuvo en cuenta el hecho de que el demandante, en su condición de inmigrante irregular privado de libertad, estaba en 
gurarse a los menores de una familia en situación administrativa irregular la asistencia médica que sea necesaria, sin que sea exigible ningún requisito en relación con la duración de su residencia en el Estado parte ${ }^{78}$, el TEDH ha sido más restrictivo al afirmar que solo en determinadas circunstancias la negativa a proporcionar asistencia sanitaria a los inmigrantes en situación administrativa irregular puede implicar una violación del derecho a no ser sometido a tratos inhumanos o degradantes previsto en el art. 3 del Convenio ${ }^{79}$. La jurisprudencia

una situación de vulnerabilidad «agravada» para resaltar el alcance de las obligaciones del Estado (apdo. 254). Sobre esta sentencia, véase el trabajo de Gisela DE LEÓN, «Contributions and Challenges for the Inter American Court of Human Rights for the Protection of Migrants' Rights: The Case of Vélez Loor v. Panama», Inter-American and European Human Rights Journal, vol. 7, núm. 1-2, 2014, pp. 39-53.

Por el contrario, los adultos en situación administrativa irregular tienen derecho a la atención de urgencia en situaciones en las que su vida esté amenazada, mientras que para otro tipo de tratamiento el Estado podrá requerir un periodo razonable previo de residencia como condición para la prestación del servicio. Sobre la base de lo dispuesto en el art. 13.4, el Comité ha recordado que la asistencia social de urgencia debe garantizarse a todos los extranjeros sin excepción (véase las Conclusiones de 2003 respecto de Portugal). También a los inmigrantes que hayan excedido el periodo permitido de residencia y que estén bajo la jurisdicción del Estado parte (véase las Conclusiones de 2009 respecto de Italia). Los beneficiarios del derecho a la asistencia social de urgencia incluye a los extranjeros que se encuentran en el territorio en situación administrativa irregular (véase las Conclusiones de 2013 respecto de Malta).

79 También de interés en este punto ha sido la labor de la Comisión Interamericana de Derechos Humanos. En Andrea Mortlock vs. Estados Unidos (Informe núm. 63/08, caso 12.534, de 25 de julio de 2008), disponible en http://www.cidh.oas.org/annualrep/2008sp/EEUU12534.sp.htm (consultado por última vez el 17.10.2015) la Comisión se refiere abundantemente a la jurisprudencia del TEDH en la materia. La Comisión protegió a la demandante, enferma de sida, frente a la devolución a Jamaica, donde la falta de tratamiento le hubiese provocado la muerte, concluyendo que la misma vulneraba el art. XXVI de la Declaración Americana de los Derechos y Deberes del Hombre (derecho a un proceso regular) que prohíbe la imposición de penas crueles, infamantes o inusitadas (la Declaración Americana de los Derechos y Deberes del Hombre fue adoptada en el marco de la IX Conferencia Internacional Americana, celebrada en Bogotá en 1948, y está disponible en http:// www.oas.org/es/cidh/mandato/Basicos/declaracion.asp (consultado por última vez el 17.10.2015). Será interesante también la inminente decisión sobre el fondo del asunto de los Trabajadores Indocumentados en Estados Unidos, en la que los demandantes alegan que sufren un trato discriminatorio como consecuencia de una decisión de la Corte Suprema de Estados Unidos que estableció que los trabajadores indocumentados despedidos ilegalmente como represalia por haber ejercido su 
de Estrasburgo ha establecido así un umbral elevado para considerar violado este derecho, tal y como cabe deducir de la sentencia del TEDH dictada en el asunto Pretty v. Reino Unido ${ }^{80}$. Con todo, los inmigrantes en situación administrativa irregular que estén enfermos podrán invocar el art. 3 del Convenio para evitar su expulsión a países de origen que no cuenten con servicios de salud adecuados ${ }^{81}$. Sin embargo, la jurisprudencia más reciente del TEDH parece sugerir que este principio se aplica únicamente en circunstancias excepcionales ${ }^{82}$. De acuerdo con la jurisprudencia del TEDH, los derechos a la vida (art. 2 del Convenio) y al respeto a la vida privada y familiar (art. 8) pueden también resultar afectados en aquellas situaciones en las que el Estado decide no proporcionar un acceso efectivo a un nivel adecuado de salud a los inmigrantes en situación irregular, aunque por lo que respecta al art. 3 el umbral de incumplimiento establecido es, como se ha indicado, alto. Además, en el primer caso, el del derecho a la vida, deberá constatarse la existencia de una amenaza "real e inmediata», mientras que en el segundo, el relativo a la derecho a la vida privada y familiar, lo que deberá determinarse es si la vulneración provoca «efectos suficientemente adversos en su integridad física y moral ${ }^{83}$.

En la sentencia dictada en el asunto $N$. c. Reino Unido ${ }^{84}$, en contra de su aproximación tradicional de acuerdo con la cual las «circunstancias excepcionales» se referían a casos en los que con la expulsión se comprometía la

derecho a la libertad de asociación ya no tienen derecho al beneficio del pago de determinados salarios (Véase el Informe de Admisibilidad 134/11, de 20 de octubre de 2011, disponible en la siguiente dirección electrónica: http://www.oas.org/es/ cidh/decisiones/admisibilidades.asp (consultado por última vez el 17.10.2015). De 29 de abril de 2002, núm. 2346/02, ECHR 2002-III, apdo. 52.

81 Sentencia de 2 de mayo de 1997, D. v. Reino Unido, núm. 30240/96.

82 Véase la decisión de la Comisión dictada en el asunto Karara v. Finlandia, de 29 de mayo de 1998, núm. 40900/98, y las sentencias de 15 de febrero de 2000, S.C.C. v. Suecia, núm. 46553/99 de 6 de febrero de 2001, Bensaid v. Reino Unido, núm. 44599/98, ECHR 2001-I; de 14 de junio de 2003, Arcila Henao v. Holanda, núm. 13669/03; de 22 de junio de 2004, Ndangoya v. Suiza, núm. 17868/03; y de 24 de noviembre de 2004, Amegnigan v. Holanda, núm. 25629/04.

83 Sentencia de 28 de enero de 1998 (Gran Sala), Osman v. Reino Unido, núm. 23452/94. En concreto, el Tribunal afirmó lo siguiente: «For the Court, and having regard to the nature of the right protected by Article 2, a right fundamental in the scheme of the Convention, it is sufficient for an applicant to show that the authorities did not do all that could be reasonably expected of them to avoid a real and immediate risk to life of which they have or ought to have knowledge. This is a question which can only be answered in the light of all the circumstances of any particular case» (apdo. 116).

De 27 de mayo de 2008, núm. 26565/05, ECHR 2008-III. 
dignidad humana más básica, dado que la enfermedad conduciría inevitablemente a un resultado doloroso y fata ${ }^{85}$, el Tribunal resolvió un asunto relativo a un solicitante de asilo cuya solicitud había sido rechazada y que debía ser retornado, por tanto, a su país de origen. El Tribunal aclara que el art. 3 no impone a los Estados parte la obligación de proporcionar asistencia médica ilimitada y gratuita a todos los extranjeros que no tienen derecho a permanecer bajo su jurisdicción (una categoría que abarcaría prácticamente a todos los inmigrantes en situación administrativa irregular). El Tribunal argumenta, en este caso, que el art. 3 no debe imponer una carga desmesurada en los Estados miembros en lo que hace a la garantía de los derechos de naturaleza socio-económica. En el caso concreto, el Tribunal entendió que la enfermedad del demandante no había alcanzado un estado de gravedad suficiente como para que su deportación implicase la vulneración del art. $3^{86}$.

Por último, la vulnerabilidad inherente a la condición de menor motivó la inclusión de los niños en situación administrativa irregular en el ámbito de aplicación del art. 17.2 de la Carta Social Europea (Revisada) ${ }^{87}$ por parte del Comité Europeo de Derechos Sociales. En particular, según el Comité, porque el acceso a la educación es crucial en la vida diaria del niño y en su desarrollo, de tal modo que la negativa a garantizar el acceso a la misma exacerbaría su vulnerabilidad ${ }^{88}$. De este modo, el Comité ha considerado que

85 Véase el Informe de la Comisión en el caso D. v. Reino Unido, de 15 de octubre de 1996, apdo. 60.

86 Más recientemente, el asunto Tatar $v$. Suiza (sentencia de 14 de abril de 2015, núm. 65692/12) relativo a la violación de los arts. 2 y 3, fue eliminado de la lista de asuntos por la Gran Sala del TEDH. El caso se refería a la devolución a Nigeria de una madre enferma de sida con sus tres hijos.

87 Que establece que los Estados parte deberán adoptar todas las medidas que resulten ser adecuadas y necesarias para "garantizar a los niños y adolescentes una educación primaria y secundaria gratuita, así como a fomentar la asistencia regular a la escuela».

Un razonamiento semejante sirvió a la CtIADH en el asunto Caso de las Niñas Yean y Bosico vs. República Dominicana, de 8 de septiembre de 2005. La Corte entendió que el hecho de que no se le hubiese proporcionado a dos menores de ascendencia haitiana pero nacidas en República Dominicana una certificación de nacimiento y se hubiese dificultado la obtención de la nacionalidad vulneraba su derecho a la personalidad jurídica y con ello su dignidad, puesto que se negó «de forma absoluta su condición de sujeto de derechos y [se las hizo] vulnerables frente a la no observancia de sus derechos por el Estado o por particulares» (apdo. 179). En el caso concreto, la denegación de las autoridades dominicanas impedía el ejercicio del derecho a la educación de las menores, puesto que sin la certificación de nacimiento no podían acceder a la escuela. La Corte entendió que no dar acceso a la educación a los niños migrantes indocumentados suponía una 
los Estados parte deben, sobre la base del art. 17.2 de la Carta, asegurarse de que los menores en situación administrativa irregular pueden acceder efectivamente a la educación en los mismos términos que cualquier otro niño ${ }^{89}$.

En relación todavía con el derecho a la educación, en el marco ahora del $\mathrm{CEDH}$, la primera frase del art. 2 del Primer Protocolo Adicional al mismo ${ }^{90}$ estipula inequívocamente que «a nadie se le puede negar el derecho a la educación». De la lectura conjunta de este art. con el art. 14 del CEDH se deduce con claridad que la misma se aplica sobre la base del principio de no discriminación tanto a nacionales como a no nacionales que estén en el territorio de un Estado parte, a menos que haya un objetivo y una justificación razonables para un trato diferenciado. Relevantes comentaristas del $\mathrm{CEDH}$ han argumentado que no se les puede negar a los hijos de los no nacionales que se encuentren en el territorio de un Estado miembro del Consejo de Europa que han ratificado este Protocolo el derecho a recibir educación, incluso si sus padres son residentes ilegales en el mismo. De este modo, denegar a los extranjeros que podrían permanecer en el Estado parte por un periodo indefinido de tiempo (por ejemplo porque no pueden ser retornados por razones humanitarias), aun en situación administrativa irregular, la posibilidad de recibir educación primaria tendría consecuencias a largo plazo, de tal modo que el hecho de la residencia ilegal no constituye una justificación razonable para un trato diferenciado, que sería por tanto contrario al art. 2 (independiente o en conjunción con el art. 14) ${ }^{91}$.

Esta opinión contrasta, sin embargo, con la afirmación del TEDH de que si el progenitor debe ser retornado al país de origen en aplicación de la normativa de inmigración, el hecho de que el menor, debido a su edad, se

vulneración de la obligación que incumbe a los Estados parte de garantizar la educación primaria de todos los niños (apdo. 185). Dignidad y vulnerabilidad —en este caso la específica de los niños - constituyó, por tanto, el fundamento de la decisión de la Corte. El 28 de agosto de 2014 la Corte dictó una nueva sentencia relativa a la detención y expulsión colectiva de personas haitianas y dominicanas de ascendencia haitiana, incluidos menores. En la misma, la Corte se pronunció sobre la situación socio-económica de esta población y entendió que el hecho de que a menudo permaneciesen indocumentados y en situación de pobreza aumentaba su vulnerabilidad: Sentencia dictada en el Caso de las personas dominicanas y haitianas expulsadas vs. República Dominicana. Excepciones Preliminares, Fondo, Reparaciones y Costas, apdo. 17.

Asunto DCI c. Holanda, ya citado aquí.

90 De 20 de marzo de 1952, ECTS núm. 9, disponible en http://www.coe.int/en/ web/conventions/full-list/-/conventions/treaty/009 (consultado por última vez el 17.10.2015).

91 Véase, por todos: Pieter Van DIJK y Godefridus J. H. Van HOOF, Theory and Practice of the European Convention on Human Rights, $3^{\mathrm{a}}$ ed., Kluwer, La Haya, 1998, p. 654. 
vea obligado a acompañarle no supondrá una violación del art. 2 del Protocolo $1^{92}$, a menos que el momento en el que se materializa la devolución afecte negativamente a la terminación de una etapa educativa del menor y no haya una necesidad imperiosa de que la expulsión tenga lugar ${ }^{93}$, o si el menor no tuviese modo de recibir educación secundaria en el país al que va a ser devuelto/a con sus padres ${ }^{94}$. Desde otro punto de vista, el TEDH, en su sentencia dictada en el asunto Ponomaryovi v. Bulgaria ${ }^{95}$, consideró que no estaba justificada la obligación de los demandantes, motivada por su estatus migratorio y su nacionalidad, de pagar tasas escolares para acceder a la educación secundaria. El Tribunal tuvo en cuenta en particular que éstos no estaban en la misma posición que los individuos que acceden irregularmente al territorio y después reclaman el uso de los servicios públicos, incluido el acceso gratuito a la educación. Aunque los demandantes, inadvertidamente por su parte, habían perdido el derecho a residir en el país y, por lo tanto, caído en la irregularidad, las autoridades no parecían haber tenido nunca objeciones de fondo a su permanencia en Bulgaria y, aparentemente, nunca tuvieron la intención seria de deportarlos. Cualquier consideración relativa a la necesidad de revertir o controlar el flujo de inmigración irregular ${ }^{96}$ no se aplicaba a ellos. El punto de vista adoptado por el TEDH en este caso parece sugerir que no hubiese llegado a la misma conclusión si los demandantes hubiesen sido inmigrantes en situación administrativa irregular que buscaban "sacar ventaja» de los servicios públicos. Y que, en consecuencia, la limitación del acceso a de-

92 Cfr. las sentencias de 23 de octubre de 1995, Sorabjee v. Reino Unido, núm. 23938/94; de 23 de octubre de 1995, Jaramillo v. Reino Unido, núm. 24865/94; de 17 de enero de 1997, Dabhi v. Reino Unido, núm. 28627/95; y de 22 de junio de 1999, Ajayi y otros v. Reino Unido, núm. 27663/95.

93 Sentencia de 25 de marzo de 2004, Vikulov y otros v. Letonia, núm. 16870/03. En este caso, el retorno de la familia fue retrasado hasta la terminación del año escolar del hijo, lo que no implicó la vulneración del art. 2 del Protocolo 1. Véase, al respecto, Jeremy McBRIDE, Irregular Migrants and the European Convention on Human Rights, Memorandum para el Comité de Migraciones, Refugiados y Población del Consejo de Europa, AS/Mig/Inf (2005) 21, disponible en https://wcd.coe.int/ViewDoc. jsp?id=1237553 (consultado por última vez el 17.10.2015).

94 En Vikulov y otros v. Letonia el hecho de que el menor pudiese recibir educación secundaria en el país al que iba a ser devuelto con sus padres fue considerado muy relevante por el Tribunal.

95 Sentencia de 21 de junio de 2011, núm. 5335/05, ECHR 2011-III.

96 Que es, como ya se ha señalado, una facultad de los Estados que deberá, en todo caso, respetar los límites impuestos por el Derecho internacional (en particular el Derecho Internacional de los Refugiados y el DIDH). 
terminados derechos sociales —incluido, parece, el derecho a la educación secundaria - como un medio para controlar la inmigración irregular podría no ser contrario a las obligaciones asumidas por los Estados parte en el CEDH.

\section{III. ¿̇UN DIÁLOGO VERTICAL? LOS TRIBUNALES CONSTITUCIONALES DE LOS ESTADOS MIEMBROS FRENTE A LA CUESTIÓN DE LA GARANTÍA DE LOS DERECHOS SOCIALES DE LOS INMIGRANTES EN SITUACIÓN ADMINISTRATIVA IRREGULAR: ESPECIAL REFERENCIA AL CASO ESPAÑOL}

Tal y como se advertía en las primeras líneas de este trabajo, la competencia para la conformación del estatuto de los inmigrantes en situación administrativa irregular no ha sido atribuida a las instituciones de la $\mathrm{UE}^{97}$. Esa competencia sigue en manos, por tanto, de los Estados miembros, que deberán tener en cuenta, a la hora de desarrollarla, de un lado, los límites marcados por el DIDH y, de otro, los establecidos por sus respectivos Derechos internos. En particular, por las normas de rango constitucional. Creemos que tiene interés, por ello, referirnos, sin ánimo de exhaustividad, a cómo los Tribunales Constitucionales han contribuido a marcar esos límites y, en concreto, al papel que las nociones de vulnerabilidad y/o dignidad han jugado en este ámbito, centrándonos, fundamentalmente, en la doctrina asentada al respecto por el Tribunal Constitucional (TC) español.

El art. 13.1 de la Constitución Española de 1978 señala que los extranjeros gozarán en España de las libertades públicas que garantiza el Título I en los términos que establezcan los tratados y la ley ${ }^{98}$. Se remite, por tanto,

97 A pesar de ello, se trata de una cuestión que ha preocupado, por ejemplo, a la Agencia de Derechos Fundamentales de la UE. Prueba de ello es su Informe titulado Fundamental rights of migrants in an irregular situation in the European Union, publicado en el año 2011 y disponible en la siguiente dirección electrónica: http://fra.europa.eu/en/ publication/2012/fundamental-rights-migrants-irregular-situation-european-union (consultado por última vez el 17.10.2015).

98 Otros textos constitucionales de los Estados miembros de la UE contienen disposiciones semejantes. Así, de acuerdo con el art. 191 de la Constitución belga: «(t) out étranger qui se trouve sur le territoire de la Belgique jouit de la protection accordée aux personnes et aux biens, sauf les exceptions établies par la loi». El texto de la Constitución está disponible en la siguiente dirección electrónica: http:// www.senate.be/doc/const_fr.html (consultado por última vez el 17.10.2015). Esta disposición ha sido interpretada por el Tribunal Constitucional belga de tal modo que únicamente aquellas diferencias de trato que estén justificadas de modo obje- 
de un lado, a las obligaciones internacionales convencionalmente asumidas por España, y, de otro, al desarrollo legislativo posterior. En nuestro caso, a lo dispuesto en la Ley Orgánica 4/2000, de 11 de enero, sobre derechos y libertades de los extranjeros en España y su integración social ${ }^{99}$ (LOEX). El TC ya advirtió en $1985^{100}$ que el mencionado "párrafo 1 del art. 13 de la Constitución no significa que los extranjeros gozarán sólo de aquellos derechos y libertades que establezcan los tratados y las leyes [...] Significa, sin embargo, que el disfrute por los extranjeros de los derechos y libertades reconocidos en el Título I de la Constitución [...] podrá atemperarse en cuanto a su contenido a lo que determinen los tratados internacionales y la Ley interna española. Pero ni siquiera esta modulación o atemperación es posible en relación con todos los derechos, pues "existen derechos que corresponden por igual a españoles y extranjeros y cuya regulación ha de ser igual para ambos" [...] así sucede con aquellos derechos fundamentales «que pertenecen a la persona en cuanto tal y no como ciudadano» o, dicho de otro modo, con "aquellos que son imprescindibles para la garantía de la dignidad humana que conforme al art. 10.1 de nuestra Constitución constituye fundamento del orden político español” ${ }^{101}$. Es doctrina constitucional consolidada, en consecuencia, que resulta necesario distinguir, cuando hablamos de la titularidad de los derechos de los extranjeros, tres categorías de derechos diferentes ${ }^{102}$. Sin embargo, debe tenerse en cuenta, como apunta DIAZ CREGO, que «si bien esta jurisprudencia del TC acota determinados ámbitos de igualdad entre españoles y extranjeros [...] el punto de partida del Alto Tribunal no es otro que la desigualdad jurídica de ambos colectivos; una desigualdad sobre la que el TC construye ciertas excepciones, sin ter-

tivo y razonable tendrán amparo constitucional: véase, por ejemplo, su sentencia 153/2007, de 12 de diciembre de 2007, disponible en la siguiente dirección electrónica: http://www.const-court.be/public/f/2007/2007-153f.pdf (consultado por última vez el 17.10.2015).

99 BOE, núm. 10, de 12 de enero de 2000, p. 1139. La ley supuso una revisión profunda de la Ley Orgánica 7/1985, de 1 de julio, sobre derechos y libertades de los extranjeros en España (BOE núm. 158, de 3 de julio de 1985, p. 20824).

100 Tribunal Constitucional (Pleno), sentencia 99/85, de 30 de septiembre.

101 Ibid., fundamento jurídico 2.

102 Puede verse un estudio detallado de la jurisprudencia constitucional en Pedro SERNA BERMÚDEZ, "La dignidad de la persona: un estudio jurisprudencial», Persona y derecho: Revista de fundamentación de las Instituciones Juridicas y de Derechos Humanos, núm. 41, 1999, pp. 13-78. 
minar de perfilar por qué la excepción se refiere a un determinado derecho y no a otro» ${ }^{103}$.

La titularidad de los extranjeros de un primer grupo de derechos está excluida por el propio art. 13, que señala que únicamente los españoles serán titulares de los derechos reconocidos en el art. 23, salvo lo que, atendiendo a criterios de reciprocidad, pueda establecerse por tratado o ley para el derecho de sufragio activo y pasivo en las elecciones municipales. Se trata de los derechos de participación política y acceso a funciones y cargo públicos. A un segundo grupo se refería la sentencia dictada en el caso Bowitz, que acabamos de citar. Se trata de un grupo de derechos indisolublemente unido, precisamente, a la dignidad del ser humano. Por ello, todos, nacionales, extranjeros en situación regular o irregular y apátridas, serán titulares de los mismos. Un tercer grupo de derechos lo constituyen «aquellos derechos en los que la ley y los tratados han de configurar su contenido cuando se ejercitan por extranjeros [...] No obstante, en tanto en cuanto los derechos fundamentales son del individuo, la modulación que se puede introducir al ejercicio por extranjeros nunca podrá llegar hasta hacer desaparecer el derecho o hasta desfigurarlo haciéndolo irreconocible» ${ }^{104}$.

¿A qué categoría pertenecen los derechos sociales? Lo cierto es que la LOEX, que parece partir de la igualdad entre extranjeros y nacionales en el disfrute de todos los derechos, concreta en cada caso las particularidades a las que se somete cada uno de ellos cuando se trata de determinar su titularidad por parte de los extranjeros. Y esa concreción, que en este trabajo analizaremos en relación únicamente con los derechos sociales, ha ido variando con el tiempo y en la misma ha tenido un peso importante la jurisprudencia del $\mathrm{TC}^{105}$.

103 María DÍAZ CREGO, «El derecho a no ser discriminado por razón de la nacionalidad: ¿Un derecho de los extranjeros?», Revista Española de Derecho Constitucional, núm. 89, 2010, pp. 115-155, p. 118.

${ }^{104}$ Luis LÓPEZ GUERRA, et al., Derecho constitucional, volumen I, El ordenamiento constitucional. Derechos y deberes de los ciudadanos, Tirant lo Blanch, Valencia, 2003, p. 169.

105 También en Francia, por ejemplo, el Consejo Constitucional ha decidido sobre la extensión de determinados derechos sociales a los inmigrantes. Así, ya en 1990 resolvió que era inconstitucional privar a los extranjeros (en este caso en situación administrativa regular) del acceso a determinados beneficios sociales: cfr. la Sentencia de 22 de enero de 1990, núm. 89-269, disponible en la siguiente dirección electrónica: http://www.conseil-constitutionnel.fr/conseil-con..decision-n-89-269-dc-du-22-janvier-1990.8711.html (consultado por última vez el 17.10.2015), en particular los apdos. 32-36. 
Así, una primera reforma de la LOEX, producida transcurridos apenas unos meses desde su entrada en vigor ${ }^{106}$ introduciría la condición de residencia legal para el ejercicio de los derechos de sindicación, huelga y la educación no obligatoria de menores de edad. La reforma fue objeto de 9 recursos de inconstitucionalidad, resueltos mediante 8 sentencias del TC en el año $2007^{107}$, que se incorporarían a una nueva reforma de la LOEX en $2009^{108}$.

Tal y como se ha señalado ${ }^{109}$, la jurisprudencia del TC ha acudido al concepto de dignidad humana para establecer distintas categorías de derechos en función de su titularidad. Ha afirmado, en este sentido, que si bien todos los derechos son inherentes a la dignidad humana, existe la posibilidad de establecer distintas graduaciones cuando hablamos de la conexión entre dignidad y derechos. El grado de conexión, en concreto, derivará del análisis del contenido esencial del derecho y de su relación con la idea de dignidad. Entre los criterios a tener en cuenta para realizar dicha determinación está acudir a lo dispuesto en los tratados internacionales de los que sea parte España ${ }^{110}$. Este "aperturismo» ha sido señalado por la doctrina como

106 Producida mediante la Ley Orgánica 8/2000, de 22 de diciembre (BOE, núm. 307, de 23 de diciembre de 2000, p. 45508).

107 Tal y como recuerda la doctrina, las sentencias 236/2007, 259/2007 y 269/2007 declararon «inconstitucional y nula la imposición de la condición de residencia en relación con los derechos a la educación, huelga y asistencia jurídica gratuita» y se limitó a declarar inconstitucional, pero sin anular los preceptos, la restricción del derecho de sindicación a los inmigrantes residentes legales: Itziar GÓMEZ FERNÁNDEZ, «Los inmigrantes como titulares de derechos sociales», Revista CEF Legal, núm. 133, 2008 , pp. 133-164, p. 138. Sobre la cuestión del estatuto jurídico de los extranjeros en España, véase también: Herminio LOSADA GONZÁLEZ, «Estatuto legal de los extranjeros», en Alberto PALOMAR OLMEDA (coord.), Tratado de Extranjería. Aspectos civiles, penales, administrativos y sociales, $4^{\mathrm{a}} \mathrm{ed}$., tomo I, Aranzadi, Cizur Menor, 2010, pp. 199-272 y María del Camino VIDAL FEITO, Constitución y extranjería, CEPC, Madrid, 2002.

${ }^{108}$ Mediante la Ley Orgánica 2/2009, de 11 de diciembre (BOE, núm. 299, de 12 de diciembre de 2009, p. 104986). El Parlamento de Navarra recurrió ante el TC la restricción del derecho a la educación postobligatoria a los mayores de 18 años, por considerar que la misma vulnera el art. 27 de la Constitución Española, que garantiza que «todos» tienen derecho a la educación. El recurso ha sido desestimado mediante la Sentencia del Tribunal Constitucional (Pleno) 155/2015, de 9 de julio.

109 GÓMEZ FERNÁNDEZ, op. cit., nota 106, p. 140.

${ }^{110}$ Un criterio que, por lo demás, establece el art. 10.2 de la Constitución. Debe tenerse en cuenta, además, que el Estado no está sólo obligado por las normas 
un argumento en favor del reconocimiento de derechos fundamentales «a todos los extranjeros que se hallen en el país», dada «su predisposición favorable al desarrollo de la universalidad y del reconocimiento del principio según el cual a cada ser humano se le debe garantizar, allá donde se encuentre, un núcleo esencial de derechos que son inviolables» ${ }^{111}$. La idea de dignidad humana, a la que se refiere el art. 10.1 de la Constitución española ${ }^{112}$, ha servido desde el principio al TC para establecer que en determinadas ocasiones no son admisibles las distinciones fundadas en la ciudadanía, dado que para la garantía de aquella resultará imprescindible asegurar la igualdad completa entre extranjeros y españoles ${ }^{113}$.

Con todo, la labor del TC ha sido casuística. No se ha establecido un catálogo de derechos incardinables en las categorías segunda y tercera a las que se ha hecho referencia. Así, por lo que hace a los derechos sociales, ha establecido que los extranjeros en situación administrativa irregular no tienen derecho al trabajo ni derecho de acceso a determinadas prestaciones de la Seguridad So-

convencionales en materia de derechos humanos, sino también "por la interpretación que de dichas normas hayan hecho los órganos de garantía que algunos de aquellos tratados han instituido en orden a supervisar el cumplimiento de las obligaciones jurídicas asumidas por los Estados parte en los mismos»: Juan Antonio CARRILLO SALCEDO, "Prólogo», en Juan Antonio CARRILLO SALCEDO (coord.), La ley de Extranjería a la luz de las obligaciones de España en Derechos Humanos, Universidad Internacional de Andalucía, Akal, Madrid, 2002, pp. 9-13, p. 10 .

111 Filippo SCUTO, «Derechos de los inmigrantes en situación irregular», Revista de Derecho Constitucional Europeo, núm. 16, 2011, pp. 215-260, p. 222.

112 Que establece que «la dignidad de la persona, los derechos inviolables que le son inherentes, el libre desarrollo de la personalidad, el respeto a la ley y a los derechos de los demás son fundamento del orden político y de la paz social». Otras Constituciones de los Estados miembros hacen también mención expresa de la dignidad de las personas. Así, el art. 1 de la Constitución portuguesa establece que «Portugal es una República soberana, basada en la dignidad de la persona humana y en la voluntad popular y empeñada en la transformación en una sociedad sin clases». También el art. 53 a) se refiere a la dignidad, en este caso de los trabajadores, para establecer que la retribución a su trabajo debe poder garantizar una existencia digna. La Constitución portuguesa está disponible en la siguiente dirección electrónica: http://www.parlamento.pt/parlamento/documents/crp1976.pdf (consultado por última vez el 17.10.2015).

113 Así lo afirmó ya en su Sentencia (Sala Segunda) 107/1984, de 23 de noviembre. 
cial derivadas de la condición de trabajador ${ }^{114}$, ni derecho a la salud, a no ser que cumplan con las condiciones establecidas en la ley ${ }^{115}$.

Otros Tribunales Constitucionales de los Estados miembros han afrontado esta misma cuestión. En el caso de la Constitución belga, el art. 23 establece, de modo explícito, que todo individuo tiene derecho a una vida digna y que, con ese fin, el legislador determinará las condiciones de ejercicio de los derechos económicos, sociales y culturales. Entre ellos, el derecho a la Seguridad Social, a la protección de la salud y a la ayuda social, médica y jurídica y el derecho a un alojamiento decente. El Tribunal Constitucional belga ha reconocido un importante margen de apreciación al legislador en esa tarea y ha evitado, por ejemplo, pronunciarse sobre la constitucionalidad de las restricciones al acceso a las ayudas sociales y a la atención médica de urgencia impuestas a los extranjeros en situación administrativa irregular, fundamentando su decisión en el hecho de que la ley que las impuso era anterior a la entrada en vigor de la redacción vigente del art. $23^{116}$. En Italia, la Corte Constitucional declaró en 2010 inadmisible el recurso interpuesto por el Gobierno de la nación contra la norma regional (toscana) que otorgaba el derecho a la asistencia médica de urgencia a los inmigrantes en situación administrativa irregular ${ }^{117}$.

114 Debe tenerse en cuenta, en este sentido, que el art. 14.3 de la LOEX establece que los extranjeros, cualquiera que sea su situación administrativa, tienen derecho a los servicios y prestaciones sociales básicas. Se ha interpretado que «básicas» resulta equiparable con «esencial para la supervivencia»: Carlos ESPLUGUES MOTA et al., $\mathrm{Na}$ cionalidad y extranjería, Tirant lo Blanch, Valencia, 2004, p. 127.

115 El Decreto-Ley 16/2012, de 20 de abril, de medidas urgentes para garantizar la sostenibilidad del Sistema Nacional de Salud y mejorar la calidad y seguridad de sus prestaciones (BOE, núm. 98, de 24 de abril de 2012, p. 31278) restringió el derecho a la asistencia sanitaria a aquellos extranjeros que contasen con permiso de residencia en España, limitando el derecho a la misma de los inmigrantes en situación administrativa irregular a las urgencias (salvo en el caso de los menores y las mujeres embarazadas). Sobre esta cuestión, véase Margarita LEMA TOMÉ, «La reforma sanitaria en España: Especial referencia a la población inmigrante en situación administrativa irregular», Eunomía. Revista en Cultura de la Legalidad, núm. 5, 2013, pp. 95-115.

116 Pierre JOASSART et al., "Bélgique», en Constitution et Droits Sociaux. Rapports Nationaux, XXXIe Table Ronde Internationale, Centre National de la Recherche Scientifique, 2015, disponible en la siguiente dirección electrónica: http://www.gerjc.univ-cezanne.fr/uploads/media/RAPPORT_TR_2015_01.pdf, (consultado por última vez el 17.10.2015).

117 Cfr. la sentencia 269/2010, de 7 de julio de 2010, disponible en la siguiente dirección electrónica: http://www.cortecostituzionale.it/actionSchedaPronuncia.do?an- 


\section{CONCLUSIONES: «EPPUR SI MUOVE!»}

Las migraciones son un fenómeno paradójico. Aunque la humanidad ha convivido con ellas desde siempre, las sociedades de acogida han tendido a mirar con desconfianza al extranjero. Con la aparición del Estado como sujeto moderno, esa desconfianza se trasladó paulatinamente a las normas que trataban de regular la entrada, permanencia y salida de los extranjeros del territorio. Así, los Derechos internos han ido incorporando poco a poco entre sus objetivos el de someter a sucesivas restricciones la entrada de extranjeros en el territorio del Estado. Se trata de un proceso que parece consolidarse hacia la segunda mitad del siglo $\mathrm{XIX}^{118}$ y que ha cristalizado en un principio de Derecho internacional en virtud del cual los Estados están facultados para establecer controles en relación con la entrada, permanencia y salida de los extranjeros de su territorio. Y también para determinar el estatuto jurídico que correspondía a los extranjeros que permanecen en el territorio en situación administrativa irregular. En el ámbito europeo, la cesión de esa competencia en materia migratoria, que ha sido considerada el último bastión de la soberanía $^{119}$, a las instituciones de la UE, ha traído consigo, en relación con la inmigración irregular, una política común amplia, aunque no exclusivamente, centrada en la prevención, el control y la criminalización del fenómeno. Una política común donde la protección de los derechos de los inmigrantes en situación administrativa irregular se ha visto marginada.

Existe en el ámbito internacional, sí, un principio general del Derecho internacional que permite a los Estados adoptar sus propias normas cuando regulan las condiciones que los extranjeros deberán cumplir para ingresar en su territorio y permanecer en él. Retienen estos, por tanto, la facultad de expulsar del mismo a los que se encuentren en él en situación administrativa irregular ${ }^{120}$. No se ha consagrado aún, en ningún instru-

no=2010\&numero=269, (consultado por última vez el 17.10.2015). La Corte recuerda en su sentencia que existe un núcleo irreductible del derecho a la salud previsto en la Constitución como ámbito inviolable de la dignidad humana (apdos. 4.1 y 6.1).

118 François RIGAUX, «L'immigration: Droit International et droit fondamentaux», en VV.AA., Les droits de l'homme au seuil du troisième millénaire. Mélanges en hommage à Pierre Lambert, Bruylant, Bruselas, 2000, p. 699.

119 DAUVERGNE, op. cit., nota 17, p. 4.

${ }^{120}$ Una facultad que, no obstante, no deja de estar sometida a límites. De los mismos se ha ocupado la Comisión de Derecho Internacional (CDI) al elaborar un Proyecto de artículos sobre la expulsión de extranjeros que fue sometido a la AGNU en 2014 y cuyo art. 13 establece la obligación de los Estados de respetar la dignidad humana de los extranjeros sometidos a un procedimiento de expulsión. El proyecto de ar- 
mento jurídico internacional de carácter vinculante, un derecho individual a elegir como país de residencia un país distinto del país de nacionalidad. Y, en consecuencia, depende también de los Derechos internos el estatuto de derechos de los que gozarán los inmigrantes indocumentados. Y no es infrecuente que, movidos por la convicción de que lo contrario generaría un "efecto llamada» no deseado por ellos y que, sobre todo recientemente, amparados por las restricciones que parece imponer la crisis económica, los Estados reserven el disfrute de determinados derechos de naturaleza social y económica a sus nacionales o, en el mejor de los casos, a los extranjeros que se encuentran en situación administrativa regular. Esta opción de política migratoria contrasta con la tendencia de los órganos de protección internacional de derechos humanos que han asumido la situación de especial vulnerabilidad en la que se encuentran los migrantes indocumentados y que han resuelto que la dignidad inherente al ser humano ${ }^{121}$ no debe verse comprometida.

Los tratados de derechos humanos - y esto incluye a la Carta de Derechos Fundamentales de la UE - tienden a potenciar un sistema de derechos que contempla como titulares de los mismos a todas las personas, nacionales o extranjeras, con independencia de su situación migratoria ${ }^{122}$. Y los órganos de protección creados por esos tratados han jugado un papel esencial en relación con la dignificación y humanización de su situación ${ }^{123}$. De modo directo o indirecto, vulnerabilidad y dignidad humana han sido invocadas por el Comité de Derechos Sociales, el TEDH y el TJUE como una "guía legal» para garantizar determinados derechos sociales al colectivo formado por inmigrantes en situación administrativa irregular. La misma noción ha sido invocada por los órganos del sistema interamericano de derechos humanos y, ya en el plano nacional, por los Tribunales Constitucionales de los Estados miembros de la UE. Todos ellos han contribuido, así, a asentar la idea de que la dignidad humana

tículos está disponible en la siguiente dirección electrónica: http://legal.un.org/ilc/ texts/9_12.shtml (consultado por última vez el 17.10.2015).

121 Tomamos la expresión del Preámbulo de Pacto Internacional de Derechos Civiles y Políticos, adoptado y abierto a la firma, ratificación y adhesión por la Asamblea General en su Resolución 2200 A (XXI), de 16 de diciembre de 1966 y disponible en la siguiente dirección electrónica: http://www.ohchr.org/SP/ProfessionalInterest/Pages/ CCPR.aspx (consultado por última vez el 17.10.2015).

122 SCUTO, op. cit., nota 111, p. 13.

123 Potenciando así su participación, todavía insuficiente a todas luces, en la universalidad de los derechos humanos: Gregor NOLL, "Why Human Rights Fail to Protect Undocumented Migrants», European Journal of Migration and Law, núm. 12, 2010, pp. 241-272, p. 242. 
es central a la hora de imponer la protección de los derechos fundamentales de los migrantes en situación administrativa irregular.

Los avances no son, con todo, lineales, y están condicionados por la casuística. A pesar de ello, hay cierta coincidencia en considerar que se imponen obligaciones adicionales cuando se trata de colectivos, como los migrantes indocumentados, que están en situación de especial vulnerabilidad. Y es posible deducir algún mínimo común denominador, por básico que este sea, relativo a la obligación de garantizar, por ejemplo, el bienestar de los menores (un grupo que ha sido identificado en general como especialmente vulnerable en la jurisprudencia analizada aquí). Dignidad y vulnerabilidad son, en definitiva, los mimbres sobre los que, en nuestra opinión, podría llegar a consolidarse un estándar mínimo de derechos para el colectivo del que nos hemos ocupado en estas páginas. 